\title{
Asymmetry of Reputation Loss and Recovery under Endogenous Relationships: Theory and Evidence*
}

\author{
by \\ Takako Fujiwara-Greve \\ Department of Economics \\ Keio University, \\ Henrich R. Greve \\ Department of Entrepreneurship \\ INSEAD, \\ and \\ Stefan Jonsson \\ Department of Business Studies \\ Uppsala University
}

January 21, 2010

\begin{abstract}
We formulate a dynamic investment model where investors can easily change firms (funds) and firms' actions are subject to imperfect monitoring. We show that there is an asymmetry of fast reputation loss and slow reputation recovery, even without informational externalities. The key factor is endogenous relationships. It is easy to lose customers but it is not easy to get them back, because without an ongoing relationship, one's belief is likely to be the same as the one at the time of separation. For recovery, new entrants or reputation loss of another firm is needed. We give empirical evidence, at the firm level, that asymmetry of investor movements exists and is likely to be caused by endogenous relationships.
\end{abstract}

Key words: reputation, asymmetry, endogenous relationships.

JEL classification: C 73 (stochastic and dynamic games), D 82 (asymmetric and private information).

\footnotetext{
*We thank Kiminori Matsuyama for the reference to Veldkamp (2005) that opened our way to look at the empirical phenomenon of asymmetry. We also thank Premiepensionsmyndigheten (PPM) and especially Marcela Cohen Birman for generously providing data. Takako Fujiwara-Greve gratefully acknowledges the research fund from Keio Economic Society.
} 


\section{Introduction}

Dynamic games with endogenous partner changes are emerging research fields. (See for example, Ghosh and Ray (1996), Kranton (1996a,b), and Fujiwara-Greve and Okuno-Fujiwara (2009).) In this paper we consider investment situations, which is a natural and important application of endogenous partner changes, and examine the structure of dynamic reputation change. In particular, we show an asymmetry of the reputation dynamic, that reputation loss is fast while reputation recovery is slow, without informational externalities such as herding and endogenous information. Instead the endogeneity of partnerships creates the asymmetry. In a homogeneous population of potential partners, once a partnership is terminated, there is no reason to voluntarily return to the old partner. Recovery needs a positive push, such as new entrants or reputation loss for other partners.

Our model, in brief, is a multiple-principal-multiple-agent model. Principals are called investors and agents are called (investment) firms. Investors are free to choose which firm to invest in according to their private information history of the firms they had experienced. All investors choosing the same firm observe the same signal of the firm, and thus there are no informational externalities.

Our model is appropriate in many economic transaction situations. For example, noninstitutional investors rely on easily available information and do not conduct costly and systematic information gathering. Likewise, consumers facing experience goods such as restaurants and school choice rely on easily available information.

Slow booms and sudden crashes have been noted in many areas of the economy: financial crises $^{1}$, economic growth ${ }^{2}$, and labor markets ${ }^{3}$, among others. Such macroeconomic phenomena can be mainly due to informational externalities because of the large set of stakeholders including institutional players and the abundance of public information on macroeconomic variables. We give a new empirical example of asymmetric loss and recovery of reputation in a single market with non-institutional investors and limited public information. Our example is taken from the market of mutual funds in the Swedish pension system from 2000 to 2006 . It shows a fast loss of a firm reputation with a prolonged recovery period, as predicted by our theoretical analysis.

\footnotetext{
${ }^{1}$ See for example, Veldkamp (2005).

${ }^{2}$ See for example, Van Nieuwerburgh and L. Veldkamp (2006).

${ }^{3}$ See for example, Neftci (1984) and McKay and Reis (2008).
} 
Our model is not only useful in showing the asymmetry of reputation dynamic but also to cast a new light on punishment structures in repeated relationships with imperfect monitoring. Hirshman's (1970) theory of "Exit or Voice" can be made rigorous by showing when exit should be used and when voice should be used.

To place our paper in the literature, we compare our analytical framework with the ordinary repeated game literature and also compare our result with the literatures on herding, endogenous information, and endogenous partnerships.

The ordinary repeated game literature with imperfect monitoring ${ }^{4}$ does not give a rationale to the asymmetric reputation dynamic. This is because the players are fixed in the game throughout and thus their strategies can control the necessary length of punishment after a bad signal. However, when one can exit from an interaction and the information is updated if and only if one is in the partnership, the punishment length is no longer fully controllable. After exit, players cannot return to the relationship rationally, i.e., based on the belief of future behavior updated by information. For recovery, new entrants who can do experimentation or bad news of another player is needed for the players to return. This creates the asymmetric speed of collapse and recovery of transactions.

Herding and endogenous information can imply asymmetry, but the driving factors are different from our model, and the resulting action path at the individual level is also different. The informational externality gradually affects investors even at the time of reputation loss, since people react to how others have acted before. The asymmetry results because it takes even longer time to recover, since the small scale of transactions generates little new information that people can react to. In our endogenous relationship model, by contrast, the reaction is quick at the loss of reputation since investors are reacting directly to their own observation of a signal and not waiting to see how others react.

In reality, however, the perception of what news amounts to a "bad" signal can vary across investors, so it is possible that some react later than others. But they wait for a critical amount of news, not for others' reactions. This can be tested by looking at the relation between news and transactions, and between transactions across time. In our empirical specification, we control for these effects in order to isolate the endogenenous partnership effect.

\footnotetext{
${ }^{4}$ See the classical literature of Klein and Leffler (1981), Green and Porter (1984) and Abreu, Pearce and Stachetti (1986). More recent papers are Ely and Välimäki (2002) and Mailath and Morris (2002).
} 
Finally, let us mention the existing literature on endogenous partnerships. The main focus in that literature (e.g., Ghosh and Ray, 1996) is to construct cooperative equilibria when one can easily run away without carrying information to future partnerships. The same informational structure (no information flow to future partnerships) is assumed in our model, but we also add imperfect monitoring within a partnership as well as one-to-many relationships. This type of endogenous partnership game has not been analyzed before.

The paper is organized as follows. Section 2 presents a model of endogenous partnerships, and section 3 shows all-effort pure-strategy equilibrium. Section 4 presents the evidence from our analysis of the Skandia scandals. Section 5 concludes the paper.

\section{Model}

Consider a continuum of homogeneous investors (principals) of measure 1 and a finite number $N>1$ of ex-ante homogeneous investment firms (agents) playing the following infinite-horizon game. Time is discrete and denoted as $t=1,2, \ldots$ At the beginning of the game, all investors are "newcomers" who do not have information regarding any firm's past behavior. At the end of each period, $(1-\delta)$ (where $\delta \in(0,1)$ ) of the investors leave the market for exogenous reasons, which we call "death". Each dead investor is replaced by a newcomer so that the population size of the investors is the same over time. A newcomer investor chooses a firm randomly to start investing, and after that she chooses whether to keep investing in the same firm or move to another firm, depending on her observations. Since each investor has only one partner firm, but a firm can have many customers, our model is a one-to-many relationship model. ${ }^{5}$ We assume that, in each period, investors choose trust decisions simultaneously.

The simultaneity (or independence) of investors' trust decisions can be justified by the information structure, which we now describe. We assume that investors do not actively gather detailed information of the firms' actions, and instead they rely on easily available information. This is the case, for example, if the investors are "amateurs" with limited resources to investigate. It is also possible that the cost of detailed information is high or that disclosure requirements are weak. For example, for mutual funds it is difficult to know how other investors are acting currently because their actions do not influence the fund value, and the fund size is

\footnotetext{
${ }^{5}$ If, instead, each investor chooses a set of firms, it is many-to-many relationships. A similar analysis can be done in that case if we assume that each investor chooses actions independently at each firm.
} 


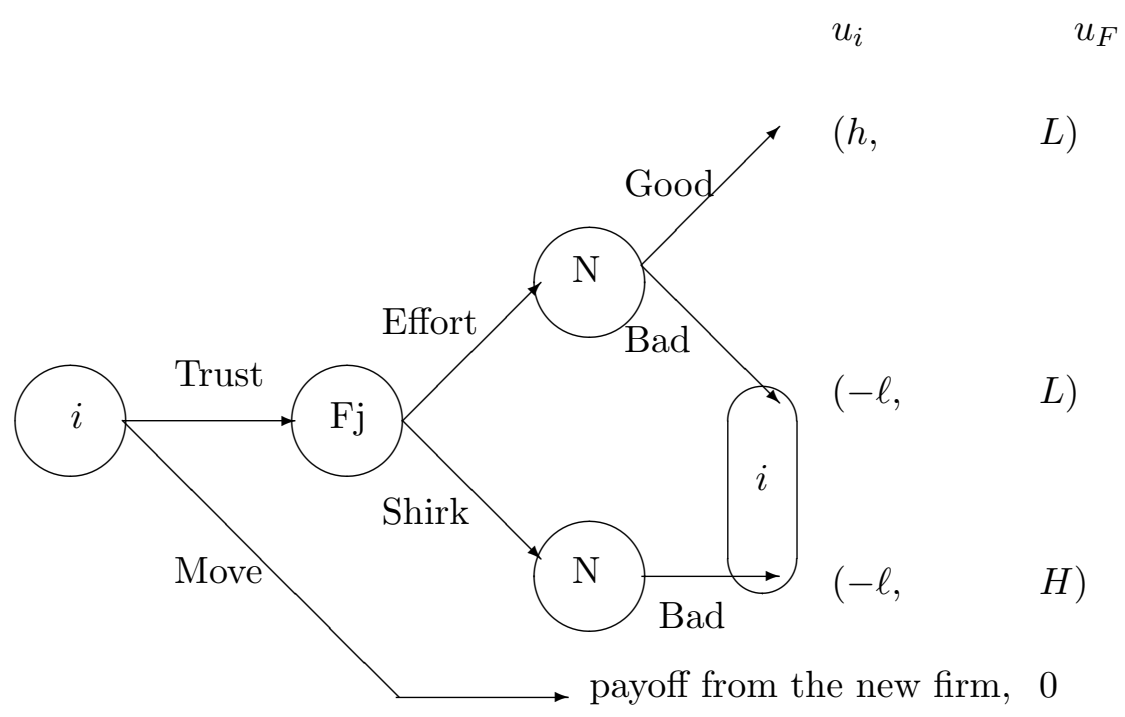

Figure 1: One-shot game structure between an investor $i$ and a firm $\mathrm{Fj}$

not disclosed frequently. This is different from stock markets, where the price movements are suggestive of the actions of other investors. There can also be a systemic reason. In our case of the Swedish pension system, orders of buy or sell are pooled and then executed as a batch. Hence individual investors cannot know the current actions of other investors.

After investors' choices, each firm chooses whether to make effort (action "Effort") or not (action "Shirk") in managing the investment. We assume that a firm cannot discriminate among its customers (those investing in the relevant firm) and chooses the same action against all customers. This is the case, for example, if a firm manages a fund that pools all customers' investment, as in mutual funds. Effort is more costly to the firm than Shirk but generates more payoff to the investors. Hence, the one-shot extensive form game between an investor and a firm is essentially the Trust game (e.g., Kreps, 1990). See Figure 1.

Firms' actions may not be perfectly observable to investors, and instead we assume that each firm's "reputation signal" is observed. In particular, we focus on the "undeserved loss" case of Jonsson et al. (2009). Each period, with a small probability, a randomly selected firm may obtain a bad signal, which is not fully correlated with its performance. Jonsson et al. (2009) recorded such a case in Swedish mutual fund market in which an insurance company called Skandia had a managerial compensation scandal, causing mutual funds with the Skandia brand to be affected. There is abundance of similar examples of loss of reputation by association. ${ }^{6}$

\footnotetext{
${ }^{6}$ For example, the Enron scandal tainted the overall reputation of its auditor Arthur Andersen, not just that of the Houston office that handled the Enron account. Martha Stewart's conviction of insider trading harmed the business of Martha Stewart Living, which sells household products.
} 
Specifically, we assume a simple two-signal model; each firm may experience one out of two signals, Good or Bad, at the end of each period. Since we focus on group-symmetric strategies such that players in a group (all firms or all investors) choose the same pure-strategy, let us describe the signal structure of a firm, when all other firms are making effort. If a firm shirked while all others made effort, the Bad signal is assumed to be generated for sure. ${ }^{7}$ If all firms made effort, we assume that a randomly selected firm may still experience the Bad signal with a small probability, due to the "undeserved loss" of reputation. To formulate this structure, suppose that with probability $1-\epsilon$, all firms (making effort) obtain the Good signal, and that with probability $\epsilon / N$, each firm gets the Bad signal for some $\epsilon \geqq 0$. The idea of this signal structure is that the Bad signal is a relative reputation, hence at most one firm obtains it. The probability structure is assumed to be the same over time (i.i.d. signal). For other possible combinations of firm's underlying actions in the relevant period, the signal structure can be arbitrary, since multiple-player deviations are ignored under Nash based equilibrium notions. Note that when $\epsilon=0$, we have perfect monitoring when all firms are making effort.

Investors receive a high one-shot utility $h>0$ if the Good signal is realized at the firm they are currently trusting and a low utility $-\ell$ (where $\ell>0$ ) if the Bad signal is realized. This utility structure is not only a standard assumption in imperfect monitoring repeated games to warrant that investors cannot infer the underlying action from the realized utility, but also a formulation to incorporate the psychological effect of the reputation signal. The one-shot expected utility of a customer of an arbitrary firm $j$ when all firms are choosing Effort is $\left(1-\epsilon+\sum_{k \neq j} \frac{\epsilon}{N}\right) h-\frac{\epsilon}{N} \ell=\left(1-\frac{\epsilon}{N}\right) h-\frac{\epsilon}{N} \ell$. For simplicity, we assume that there is no cost to moving one's investment to another firm. ${ }^{8}$

Finally, customers ${ }^{9}$ of firm $k \neq j$ are assumed not to observe the signal of firm $j$. In our one-to-many relationships, this is essentially the no information flow assumption. Thus there is no informational externalities: all customers at a firm observe the same signal and no other

\footnotetext{
${ }^{7}$ It is straightforward to modify the model so that the Good signal is also stochastically generated when a firm shirks with a smaller probability than the one when the firm made effort.

${ }^{8}$ This assumption (almost) holds in our empirical case, where investors can use the web or phone calls to change funds. It can be dropped if we modify the equilibrium notion, so that an investor chooses $\alpha$-best response instead of best response, and an investor's cost of moving is less than $\alpha$. An $\alpha$-best response is a strategy that gives long-run payoff not less than the payoff $-\alpha$ of any other strategy. See Radner (1980). Choosing an $\alpha$-best response is not fully rational but has a flavor of satisficing and can be appropriate in real examples.

${ }^{9}$ We distinguish an "investor" as a generic player in the investor population and a "customer" for firm $j$ as a player who is currently trusting firm $j$.
} 
investors observe that signal.

Our justification for the no information flow assumption is two-fold. First, in many real situations it is costly to investigate information regarding firms that one is not currently investing in, particularly among amateur investors with limited resources to spend on investment decisions, knowing that firms are ex-ante homogeneous. Second, the assumption is only to make the analysis simple (and strong), and the same equilibrium in which all firms make effort in every period can be more easily constructed when investors have more information. This is because it becomes easier to punish a firm with the Bad signal if investors can react to the firm even if they are not current customers. ${ }^{10}$ Note that no information flow structure gives a rationale to the random choice of a firm to trust when an investor is a newcomer or when an investor observed the Bad signal of the current firm, since there is no information regarding other firms.

Each firm is only concerned with the material payoff and not the signal per se. It prefers shirking to making effort since the latter is costly. If an investor trusts and the firm shirks, the firm gets a high payoff $H>0$ for sure. If $x_{j} \in[0,1]$ is the measure of investors who trust firm $j$, the total payoff to firm $j$ when it shirks is $H x_{j}$. If an investor trusts and the firm makes effort, the firm receives a low payoff $L>0$ such that $L<H$. The total payoff is $L x_{j}$ if $x_{j}$ of investors trust firm $j$ and it makes effort. We also assume that

$$
\left(1-\frac{\epsilon}{N}\right) h-\frac{\epsilon}{N} \ell+L>H-\ell
$$

so that (Trust, Effort) is collectively better than (Trust, Shirk) between an investor and a firm.

Firms' ability to observe each other's signal history is not relevant in our model. Instead the distribution of investors across firms (denoted as $\mathbf{x}=\left(x_{1}, x_{2}, \ldots, x_{N}\right) \in \Delta^{N-1}$, where $\Delta^{N-1}$ is the $N-1$ dimensional unit simplex) is sufficient information for payoff maximization. The logic is as follows. A firm's dynamic optimization takes into account one-shot payoff in a period and the expected continuation value. A firm's one-shot payoff is dependent only on its current customer measure. Its continuation value depends on the expected measure of outflows of customers and inflows of investors. On one hand, the outflow only depends on its signal, which is random, and the current measure of its customers. On the other hand, the inflow depends on other

\footnotetext{
${ }^{10}$ In general, more information makes it easy to sustain efficient behavior, which in this case is firms' effort. Kandori (2002) explains how difficult it is to sustain efficient behavior under imperfect monitoring. Clearly, if the signals are public (and even newcomers can observe all signals of all firms), our model reduces to an ordinary repeated game, since there is no cost of moving to a different firm.
} 


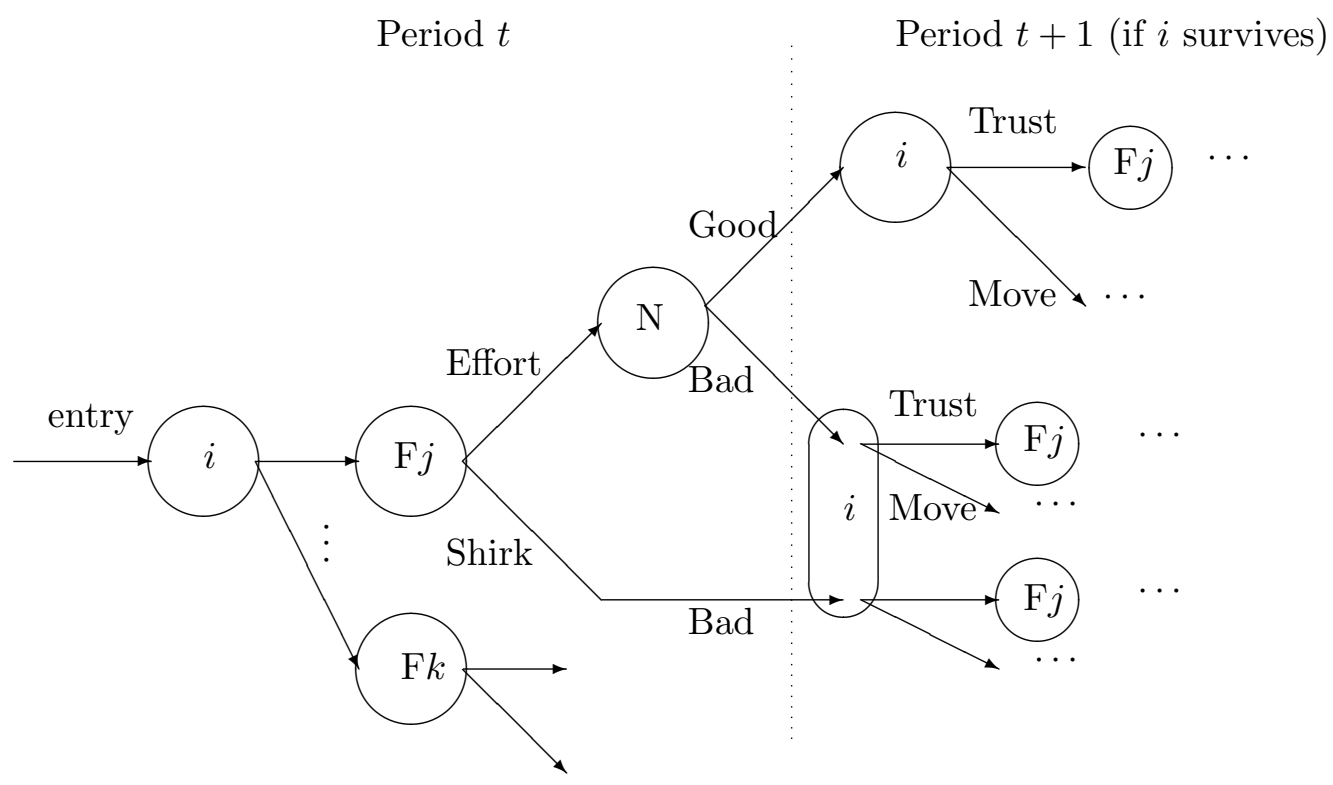

Figure 2: Outline of the endogenous-relationship game for an investor

firms' signals as well as their customer measures. Since signal structure is known and i.i.d,, it is sufficient to know the distribution of investors across firms to compute the continuation value.

The probability $\delta$ of staying in the game is the effective discount factor for each investor. Firms are active in the game forever and thus we assume that they discount payoffs by a common discount factor $\beta \in(0,1)$.

The outline of the dynamic game for an investor is depicted in Figure 2. (Due to limited space, we omitted the random death from the figure.)

\section{Sequential Equilibria}

In this section we define an equilibrium concept and derive equilibria in which all firms always make effort.

\subsection{Strategies and Equilibrium}

Definition. For each investor-firm pair, let $\tau=1,2, \ldots$ be the horizon of the partnership. A signal history for an investor at the beginning of $\tau$-th period in a partnership is

$$
h_{\tau}= \begin{cases}\emptyset & \text { if } \tau=1 \\ \left(z_{1}, \ldots, z_{\tau-1}\right) \in\{G, B\}^{\tau-1} & \text { if } \tau \geqq 2\end{cases}
$$


Definition. A strategy $s_{i}$ of an investor $i$ is a function that assigns $a_{\tau} \in\{$ Trust, Move $\}$ for each signal history $h_{\tau}$ for $\tau=1,2, \ldots$

Implicitly, we are assuming that when $\tau=0$ (which is the case when she is a newcomer or has chosen to Move), an investor randomly chooses a firm. After that, regardless of the firm chosen, an investor behaves the same way according to $s_{i}$, i.e., we focus on firm-independent strategies of investors. The firm-independence is standard in no-information-flow models (e.g., Fujiwara-Greve and Okuno-Fujiwara, 2009).

By contrast, from a firm's point of view, the relevant time horizon is the "calendar time" of the dynamic game $t=1,2, \ldots$ As we discussed in Section 2, a firm's decisions can be based only on the distribution of investors across firms at that time. For each $t=1,2, \ldots$, let $\mathbf{x}(t)=\left(x_{1}(t), x_{2}(t), \ldots, x_{N}(t)\right) \in \Delta^{N-1}$ be the distribution of investors.

Definition. A strategy $s_{j}^{F}$ of a firm $j \in\{1,2, \ldots, N\}$ is a function that assigns $b_{t} \in\{$ Effort, Shirk $\}$ for each current distribution of $\mathbf{x}(t) \in \Delta^{N}$ for $t=1,2, \ldots$

Since the dynamic game is of imperfect information with non-public signals, a natural equilibrium concept is a sequential equilibrium as in the literature, such as Abreu et al. (1986, 1990). For compositional simplicity we do not explicitly construct the belief system, but in our pure-strategy equilibrium it is clear.

Definition. A sequential equilibrium is a strategy combination of all players such that in each information set of a player,

(i) the continuation strategy of the player is optimal given the belief at the information set (a probability distribution over the decision nodes within the information set) and the continuation strategy of other players; and

(ii) the belief at the information set is probabilistically consistent with the strategy combination.

\subsection{Group-Symmetric Pure-strategy Equilibrium}

Clearly, if firms make effort after any signal history, that is efficient. (Note that even if current investors may move out, there will be some newcomers that invest in any firm after any signal history.) In this section let us derive a group-symmetric ${ }^{11}$ equilibrium in which all firms make

\footnotetext{
${ }^{11} \mathrm{~A}$ strategy combination of two groups of players is group symmetric if all players in a group use the same strategy.
} 
effort after any signal history and all investors stay at the same firm if and only if the previous signal was Good. To induce a firm's effort, customers must punish the firm if Bad signal is observed, even if the true action was to make effort. Moreover, because newcomers randomly choose a firm, even if a firm shirked, there will be a positive measure of customers in the next period. Thus, if the signal is very imprecise (large $\epsilon$ ), firms may simply give up on making effort and try to exploit newcomers every period. This can be prevented when the signal is not too disruptive, i.e., $\epsilon$ is small.

Let us define the candidate strategies for an equilibrium.

Definition. A (Markov) trigger-strategy of an investor $s_{i}^{T}$ assigns, for any $\tau=2,3 \ldots$ and any private signal history $h_{\tau}=\left(z_{1}, \ldots, z_{\tau-1}\right)$,

$$
s_{i}^{T}\left(h_{\tau}\right)= \begin{cases}\text { Trust } & \text { if } z_{\tau-1}=G \\ \text { Move } & \text { if } z_{\tau-1}=B\end{cases}
$$

Under this strategy the actions are dependent only on the previous period's signal in the private history.

Definition. A constant effort strategy $s_{j}^{E}$ for a firm $j$ assigns, for any $t=1,2, \ldots$ and any investor distribution $\mathbf{x}(t), s_{j}^{E}(\mathbf{x}(t))=$ Effort.

Proposition 1. For any $\epsilon<L(N-1) / H$, there exists $(\underline{\beta}, \underline{\delta}) \in(0,1)^{2}$ such that for any $(\beta, \delta) \geqq$ $(\underline{\beta}, \underline{\delta})$, the symmetric pure-strategy combination of $s_{i}^{T}$ for all investors and $s_{j}^{E}$ for all firms is a sequential equilibrium.

Proof: See Appendix.

The intuition is as follows. Investors are ex-ante indifferent among any firm, since all firms have the same strategy and generate the same expected utility for investors. Thus it is (weakly) optimal to move to another firm after the Bad signal. (Note that although investors are indifferent between moving and staying, if they are not moving out after the Bad signal, they cannot enforce firms' effort. See Corollary 2.)

As for firms, notice that a firm has at most three kinds of customers in each period. The first kind is newcomers who randomly chose this firm at the beginning of their lifetime. The second is "old" customers who trusted this firm in the previous period and had decided to stay. 
The third is "movers" who trusted another firm in the previous period and moved to this firm at the end of the previous period.

Since the measure of movers depends on how other firms did, an individual firm's value function does not have the recursive structure which is often utilized in the repeated game literature. To be concrete, a firm $j$ 's total expected discounted payoff when the current investor distribution is $\mathbf{x}(t)=\left(x_{j}(t), x_{-j}(t)\right)$ is formulated as follows, under the group-symmetric strategy distribution of $\left(s^{T}, s^{E}\right)$.

$$
\begin{aligned}
v\left(x_{j}(t) ; x_{-j}(t)\right)= & L x_{j}(t)+\beta\left\{(1-\epsilon) v\left(\delta x_{j}(t)+\frac{1-\delta}{N} ; x_{-j}(t+1)\right)\right. \\
& +\frac{\epsilon}{N} v\left(\frac{1-\delta}{N} ; x_{-j}(t+1)\right) \\
& \left.+\sum_{k \neq j} \frac{\epsilon}{N} v\left(\delta x_{j}(t)+\frac{1-\delta}{N}+\frac{\delta x_{k}(t)}{N-1} ; x_{-j}(t+1)\right)\right\} .
\end{aligned}
$$

To explain, the first term is this period's payoff, which only depends on its current measure of customers $x_{j}(t)$. After discounting, the continuation value from the next period on starts with a variety of customer measures. If no firm gets the Bad signal (with probability $1-\epsilon), \delta$ of the current customers stay as old customers and $\frac{1-\delta}{N}$ of newcomers randomly choose firm $j$ in the next period. There will be no movers from another firm. Thus the continuation payoff starts with the customer measure $\delta x_{j}(t)+\frac{1-\delta}{N}$. If this firm $j$ gets the the Bad signal (with probability $\left.\frac{\epsilon}{N}\right)$, then its customer measure in the next period drops to $\frac{1-\delta}{N}$. If a firm $k(\neq j)$ gets the Bad signal, then $\frac{1}{N-1}$ of $\delta x_{k}(t)$ will move to firm $j$. Hence in this case the customer measure in the next period is $\delta x_{j}(t)+\frac{1-\delta}{N}+\frac{\delta x_{k}(t)}{N-1}$. This term makes it clear that a firm's value function depends on all other firm's customer measures at each point of time. Therefore the total expected payoff function of an individual firm is not recursive on its own.

We thus take a new route to derive the total expected payoff of a firm, by solving for the total discounted expected measure of investor distribution of all firms (as a vector). Although an individual firm's measure is not solvable on its own, the vector formulation turned out to be recursive and solvable. Then $L$ times the $j$-th coordinate is the total expected discounted payoff of firm $j$, when it follows the constant effort strategy. We briefly describe how this vector specification has a recursive structure. For details see Appendix.

Let $M\left(\left(x_{1}, x_{2}, \ldots, x_{N}\right)^{\prime}\right)$ be the $N$-dimensional (column) vector ${ }^{12}$ of total discounted ex-

\footnotetext{
${ }^{12}$ The notation $\left(x_{1}, x_{2}, \ldots, x_{N}\right)^{\prime}$ stands for the transpose of the row vector $\left(x_{1}, x_{2}, \ldots, x_{N}\right)$.
} 
pected measure of customers of all firms over the infinite horizon, starting with an investor distribution $\left(x_{1}, x_{2}, \ldots, x_{N}\right)$. We can explicitly formulate this vector dynamic as

$$
M\left(\mathbf{x}^{\prime}\right)=\mathbf{x}^{\prime}+\beta\left[(1-\epsilon) M\left(\delta \mathbf{x}^{\prime}+\frac{1-\delta}{N} \mathbf{e}^{\prime}\right)+\sum_{k=1}^{N} \frac{\epsilon}{N} M\left(A_{k}(\delta) \mathbf{x}^{\prime}+\frac{1-\delta}{N} \mathbf{e}^{\prime}\right)\right],
$$

where $\mathbf{e}^{\prime}=(1,1, \ldots, 1)^{\prime}$ is the $n$-dimensional unit column vector and $A_{k}(\delta)$ is defined as

$$
A_{1}(\delta)=\left(\begin{array}{cccc}
0 & 0 & \cdots & 0 \\
\delta /(N-1) & \delta & \cdots & 0 \\
\vdots & 0 & \ddots & 0 \\
\delta /(N-1) & 0 & \cdots & \delta
\end{array}\right), A_{2}(\delta)=\left(\begin{array}{ccccc}
\delta & \delta /(N-1) & 0 & \cdots & 0 \\
0 & 0 & 0 & \cdots & 0 \\
0 & \delta /(N-1) & \delta & \cdots & 0 \\
0 & \vdots & 0 & \ddots & 0 \\
0 & \delta /(N-1) & 0 & \cdots & \delta
\end{array}\right)
$$

and so on for each $k=1,2, \ldots, n$.

This formulation is simply the vertical concatenation of (2). The current period customer distribution is $\mathbf{x}^{\prime}$. With discounting $\beta$ and with probability $1-\epsilon$, no firm experiences the Bad signal so that the distribution changes into $\delta \mathbf{x}^{\prime}$ (old customers) plus $\frac{1-\delta}{N} \mathbf{e}^{\prime}$ (newcomers). With probability $\frac{\epsilon}{N}$, one firm, say firm $k$, gets the Bad signal in this period. Then this firm will start the next period with only $\frac{1-\delta}{N}$ of newcomers, while any other firm $j$ starts the next period with $\delta x_{j}+\frac{\delta}{N-1} x_{k}+\frac{1-\delta}{N}$, where the second term is the measure of movers from firm $k$ to $j$. The first two terms are embodied in the matrix multiplication $A_{k}(\delta) \mathbf{x}^{\prime}$.

By the formulation it should be clear that $M(\cdot)$ is linear in $\mathbf{x}^{\prime}$ and stationary. Using this, we can explicitly solve for $M\left(\mathbf{x}^{\prime}\right)$. Moreover, in the long run, the $j$-th coordinate of $M\left(\mathbf{x}^{\prime}\right)$ is independent from other firms' initial measure of customers. Thus we can denote $M_{j}\left(x_{j}\right)$ as the total discounted expected measure of customers for firm $j$, dependent only on the initial measure of own customers $x_{j}$. The total discounted expected payoff of firm $j$ is then $L \cdot M_{j}\left(x_{j}\right)$. Finally, using the explicit solution of $M_{j}\left(x_{j}\right)$, we show that the sufficient condition, $\epsilon<L(N-1) / H$, implies that no firm would Shirk in one period: for any $x_{j} \geqq(1-\delta) / N$ (which is the smallest measure of customers a firm can have in a period),

$$
L \cdot M_{j}\left(x_{j}\right) \geqq H x_{j}+\beta L \cdot M_{j}((1-\delta) / N) .
$$

Corollary 1. The equilibrium long-run payoff of a firm is

$$
L \cdot M_{j}\left(\frac{1}{N}\right)=\frac{L}{N(1-\beta)} .
$$


Proof: See Appendix.

Therefore, the total discounted expected payoff is independent of $\epsilon$. This is because a firm not only loses customers stochastically but also gains customers from other firms stochastically, and in the long run these movements cancel out. This also means that the symmetric equilibrium is efficient in the long run, despite the imperfect monitoring. This is a contrast to ordinary repeated game with imperfect monitoring where the gain by other player's loss of reputation is not considered.

We also show that even though investors are ex ante indifferent among firms so that they do not have to move out after the Bad signal, in that case no firm would make effort since the condition (4) does not hold.

Corollary 2. If the measure of customers is unchanged after the Bad signal, then

$$
L \cdot M_{j}\left(\frac{1}{N}\right)<H \frac{1}{N}+\beta L \cdot M_{j}\left(\frac{1}{N}\right)
$$

for any $\beta \in(0,1)$ so that firms would not choose Effort in the first period, i.e., no move out by customers and the constant effort strategy by the firms do not constitute even a Nash equilibrium.

Proof: From Corollary 1, we have $L \cdot M_{j}\left(\frac{1}{N}\right)=\frac{L}{N(1-\beta)}$. Therefore

$$
(1-\beta) L \cdot M_{j}\left(\frac{1}{N}\right)=\frac{L}{N}<H \frac{1}{N} \Longleftrightarrow L \cdot M_{j}\left(\frac{1}{N}\right)<H \frac{1}{N}+\beta L \cdot M_{j}\left(\frac{1}{N}\right) .
$$

Therefore the combination of the Markov trigger strategy for all investors and the constant effort strategy for all firms is the unique group-symmetric pure-strategy equilibrium with constant effort by the firms.

Next, let us display how the measure of customers changes before and after a reputation loss. At the beginning of the game, all firms receive the same share of customers $\frac{1}{N}$. As long as no firm gets the Bad signal the turnover of investors does not change the symmetric investor distribution: $x_{j}(t)=\frac{1}{N} \Rightarrow x_{j}(t+1)=\delta \frac{1}{N}+\frac{1-\delta}{N}=\frac{1}{N}$. When a firm gets the Bad signal, the measure of customers of the firm decreases to $(1-\delta) / N$ in the next period and only slowly increases over time after that, until some other firm gets the Bad signal. Until then, the timesequence of customers is limited to the accumulation of newcomers, which can be expressed as 


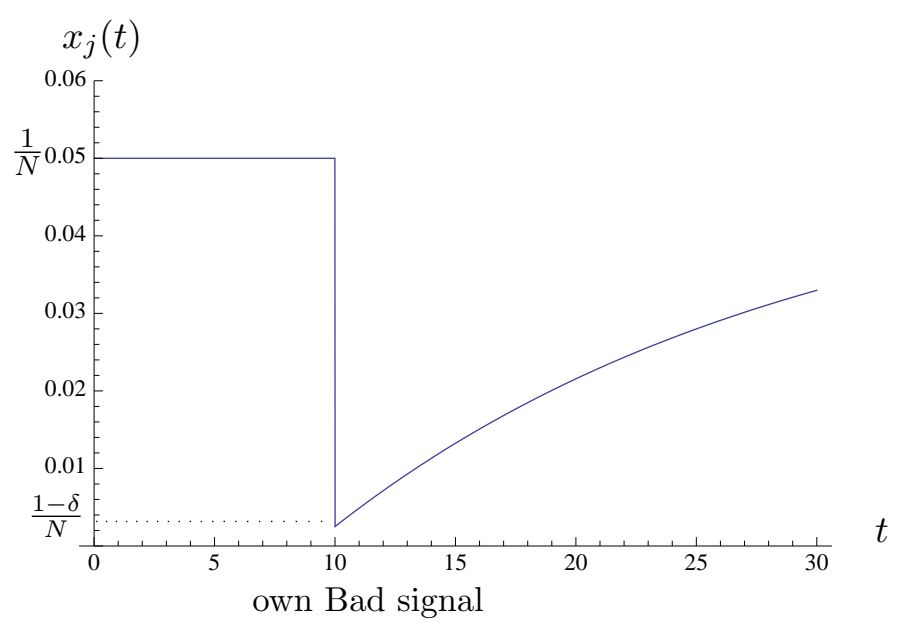

Figure 3: A reputation dynamic of customer measure $(\delta, N)=(0.95,20)$

follows.

$$
\begin{aligned}
& x_{j}(T ; j B)=\frac{1-\delta}{N}, \\
& x_{j}(T+1 ; G)=\delta x_{j}(t ; j B)+\frac{1-\delta}{N}=\frac{1-\delta}{N}(1+\delta), \\
& x_{j}(T+2 ; G)=\delta x_{j}(t+1 ; G)+\frac{1-\delta}{N}=\frac{1-\delta}{N}\left(1+\delta+\delta^{2}\right), \\
& \ldots \\
& x_{j}(T+t ; G)=\frac{1-\delta}{N} \times \frac{1-\delta^{t+1}}{1-\delta} .
\end{aligned}
$$

where $x_{j}(t ; z)$ is the measure of customers of firm $j$ in period $t$ when the previous period signal realization was $z \in\{G, 1 B, \ldots, N B\}$ and $G$ stands for the Good signal for all firms, $k B$ stands for the Bad signal for firm $k \in\{1,2, \ldots, N\}$. As the formula (5) shows, if no jump occurs, the recovery path is concave. When another firm gets the Bad signal, the curve should discretely shift upwards and start another concave path. When this firm gets the Bad signal again, the curve jumps down to $(1-\delta) / N$ and restarts the same way as above. Figure 3 depicts a path of customer measures on the equilibrium play path (from the initial measure $1 / N$ ) when firm $j$ had the Bad signal at $t=10$ and no more Bad signals are observed. Notice that it takes a long time to recover to $1 / N$.

\subsection{Weaker Punishment Equilibria}

As Hirshman (1970) argued, there are cases in which one should not punish too much. Moving out entirely (except newcomers) from a firm with the Bad signal can be an equilibrium only for 
sufficiently small $\epsilon$. When $\epsilon$ does not satisfy the condition $\epsilon<L(N-1) / H$, we should weaken the punishment.

There are at least two ways to weaken the punishment. One way is to allow an asymmetric strategy of investors so that some customers do not move out after the Bad signal. Alternatively, the same payoff sequence for firms can be generated by a symmetric behavior-strategy such that after the Bad signal the customers randomize between moving out and staying.

Let $\alpha>0$ of the investors use the trigger strategy. The remaining $1-\alpha$ of the investors use the following inertia strategy.

Definition. An inertia strategy $s_{i}^{I}$ of an investor assigns, for any $\tau=1,2, \ldots$ and any private signal history $h_{\tau}, s_{i}^{I}\left(h_{\tau}\right)=$ Trust.

This inertia strategy starts the game with a randomly chosen firm but does not change firms regardless of signal history. Assume that when an investor dies, the newcomer replacing her has the same strategy. Then the population of investors always consists of $\alpha$ of the trigger strategy investors and $1-\alpha$ of inertia strategy investors. If we use the behavior-strategy interpretation, $\alpha$ is the probability that a customer stays after the Bad signal. Note that when $\alpha=1$ the strategy combination reduces to the one in Proposition 1. Firms should not play an asymmetric strategy combination since their constant effort is the source of efficiency.

An analogous analysis to the symmetric pure-strategy equilibrium implies that firms follow the constant effort strategy if $\epsilon<\frac{L(N-1)}{\alpha H}$. Note that $\frac{L(N-1)}{\alpha H} \rightarrow \infty$ as $\alpha \rightarrow 0$. Thus, even if the probability of wrong signal $\epsilon$ increases, appropriate investor strategies can induce effort of firms.

Proposition 2. For any $\epsilon \geqq 0$ there exist $(\bar{\alpha}, \underline{\beta}, \underline{\delta}) \in(0,1)^{3}$ such that for any $\alpha \leqq \bar{\alpha}$ and any $(\beta, \delta) \geqq(\underline{\beta}, \underline{\delta})$, the strategy combination such that $\alpha$ of investors use the trigger strategy $s_{j}^{T}$ and $(1-\alpha)$ of investors use the inert strategy $s_{j}^{I}$ and all firms use the constant effort strategy $s_{j}^{E}$ is an equilibrium.

Proof: See Appendix.

Notice that the equilibrium payoff of a firm is the same as the one of the group-symmetric pure-strategy equilibrium, since the rate of losing customers upon the Bad signal does not affect the long-run payoff under the above stationary strategy combination either. Thus payoff efficiency is unchanged while the sufficient condition is weaker. 
To relate this result to Hirshman (1970), we can say that when the probability of a wrong signal $(\epsilon)$ is large, the "exit" strategy by all customers is so harsh that it destroys an efficient equilibrium. In such cases, however, we can still construct an effort equilibrium with appropriate "voice" by reducing the measure of customers but not entirely.

The weaker punishment equilibria can be also important when firms face financial constraint to keep operating (c.f. Yasuda, 2007). If firms need a certain level of payoffs in every period in order to remain in the business, the infinite horizon of the firms is no longer an assumption but must be also endogenously sustained. When the fraction of newcomers is not enough to achieve the minimum level, we can still construct an equilibrium where the necessary measure of old customers stay even after the Bad signal. In that case, however, we cannot adjust $\alpha$ freely so that there should be an upper bound to $\epsilon$ again.

\section{Firm-Level Evidence}

In this section we provide empirical evidence of asymmetry of the reputation dynamic for a firm where the reputation loss occurred by a random Bad signal. Although we have shown a variety of equilibria in the previous section, there is a common property of the equilibrium paths such that the loss of reputation is immediate while the recovery is slow unless a "push" by another firm's Bad signal occurs.

We take the example of a scandal of a large Swedish insurance firm called Skandia, which affected many other firms in other markets. We focus on a mutual fund management firm called Skandia Fonder, which was part of the Skandia group but was not implicated in the scandal. Thus it is a clear case of imperfect monitoring, and the mutual fund market itself was in a well-behaved (making effort) state during the scandal time.

\subsection{Skandia Scandals}

Skandia AB was established as a casualty insurance company in 1855 . Over the years it diversified into life insurance, unit-linked insurance, mutual fund management, and retail banking. Benefiting from the rising stock markets, Skandia AB had by the end of the 1990's grown into one of the largest global actors in the long-terms savings industry. In year 2000 Skandia was valued at over 20 billion USD, making it the second largest Swedish listed firm. Its subsidiaries 
included firms offering unit-link savings (Skandia AFS) and life insurance (Skandia Life), a bank (Skandia Banken), as well as an asset management firm (Skandia Asset Management, or SAM) and a mutual fund firm (Skandia Fonder).

Although Skandia was a hugely popular firm in 2000, media turned critical when Skandia announced the sale of its asset management firm (SAM) to the Norwegian bank DnB for SEK 3.2 billion (approximately USD 320 million) in January 2002. The reason for the media outcry was that industry observers felt the sale would indirectly hurt the customers of the life insurance business of Skandia - Skandia Life. The worth of an asset management company is largely determined by its long-term asset management contracts, and it was estimated that two-thirds of the value of SAM came from a contract with the policy holders in Skandia Life. However, all sales proceeds went directly to Skandia AB rather than to Skandia Life. While Skandia Life is an incorporated firm, its bylaws stipulates that it is run as a mutual firm which means that it cannot pay dividend to its owners when there is a surplus, but returns all profits to its policyholders. Subsequent investigations exonerated Skandia of any wrongdoing, but industry pundits interpreted the SAM deal as a way for Skandia AB to extract assets from Skandia Life, a practice that was widely seen as opportunistic.

In the April 2002 annual shareholders meeting, the management incentive programs of Skandia became intensely debated. A large institutional owner of Skandia AB published a debate article in one of the largest Swedish dailies stating their intention to vote against the suggested incentive program because they found it too expensive and not sufficiently related to the performance of the managers. Following this there was scattered media coverage of Skandia and its incentive programs during the entire spring. This was the first 'Skandia scandal', but worse events would come later.

In October 2002, there were media reports about 'apartment dealings' of the management of Skandia AB. To place this allegation in context, rental apartments in central Stockholm are extremely difficult to get. The market for such contracts has long been under government control, so contracts for rental apartments in central Stockholm are extremely valuable and often carry a hint of patronage. In this particular case the luxury apartment of the financial director of Skandia AB was to be renovated at the expense of Skandia AB without a commensurate raise in the rental cost. While this specific renovation was called off due to the bad publicity it 
generated for Skandia, the media subsequently uncovered a number of other apartment dealings. The most frequent type involved top-level managers at Skandia AB providing their children with rental apartments in real estate owned by Skandia. Public outrage was further fuelled by the memory of the recent management compensation debate, which created an impression of personal enrichment at the expense of the firm. In November 2002 one of the largest business weeklies reported from a poll of a number of market analysts that most of them had no confidence left for the CEO of Skandia AB.

In March 2003, the life insurance subsidiary of Skandia AB, Skandia Life, commissioned an independent investigation into the dealings of Skandia AB and Skandia Life, in particular the sale of SAM to DnB. At the April 2003 annual shareholders meeting of Skandia AB the shareholders forced another independent investigation into the generous incentive program and the apartment 'scandals.' The CEO of Skandia AB was fired the day after this shareholder meeting. In September 2003 the Skandia Life investigation presented allegations of wrongdoing by Skandia AB in the sale of SAM. In October, the lawyer leading the Skandia AB investigation into the apartment dealings announced as a preliminary finding that the number of hidden deals involving luxury renovations of the apartments of the management of Skandia AB was much higher than earlier reported in media. This drew intense media attention and the chief prosecutor of Sweden placed the earlier management of Skandia AB under criminal investigation in the following week.

The report on the apartment dealings was released at the end of December 2003, at which media coverage of Skandia peaked. A key finding was that the management had extracted larger bonuses than the board had sanctioned, and as a consequence the chairman of the board resigned and an extraordinary shareholder meeting was called for January 2004. Just before the end of the year, Skandia AB filed a lawsuit against its former CEO, finance director, and chairman of the board. In January 2004 a public interest group filed a class action suit against the sale of SAM by Skandia AB. In February 2004 Skandia Life, after pressure from the consumers' ombudsman, among others, decided to take Skandia AB to arbitration for SEK 2 billion of the 3.2 billion SAM sales proceeds.

These events caused media attention to Skandia to be significantly higher than normal during 2002 - 2004, and public confidence in Skandia AB was seriously eroded by the negative publicity. 
An annual survey of the perceived quality of firms by Swedish consumers (Swedish Quality Index) reported a drop of confidence in the pension operations of Skandia of almost twenty points from 2000 to 2004 , which is the largest recorded drop in confidence ratings by any firm since measurement began in 1988. Partly as a consequence, Skandia AB was acquired by the South African insurance firm Old Mutual in 2005.

It is important to note that all the scandal events occurred around a few individuals at the helm of Skandia $\mathrm{AB}$ - the CEO, the finance director and a few other managers. None of the board members or managers of the subsidiaries of Skandia were implicated in these stories. In this paper we investigate the transactions of mutual funds under the name "Skandia", but for three reasons such mutual funds have nothing to do with the above mentioned scandals. First, they were managed by an independent company called Skandia Fonder, and the board members of Skandia Fonder do not overlap with those of Skandia AB. Second, a mutual fund in Sweden, unlike a life insurance or pension fund, is not allowed to own real estate. Thus, it is impossible to have the same type of scandal at Skandia Fonder. Third, the mutual funds under Skandia brand do not own disproportionately more of the stocks of the scandal-hit firm Skandia AB than other mutual funds. Hence even if the portfolio of the mutual funds may be affected by the scandals, the effect would be the same as or less than other funds investing in Swedish stock. There is thus no rational reason to suspect that the scandals affect the mutual funds' performance.

\subsection{Data and Method}

We examine mutual fund transactions in funds with the Skandia brand under the Swedish public pension plan. We obtained data on mutual fund transactions from the Swedish public pension authority Premiepensions Myndigheten (PPM). This is the governmental authority that manages the system of mandated individual pension savings that is a part of the new Swedish pension system. In year 2000, the Swedish mandatory pension system was changed from payas-you-go where the state managed the entire pension to a defined contribution system where the individual is expected to actively manage a small part of his/her pension (Sunden, 1998, and Horngren, 2001). Two and a half percent of the annual income of every working Swede is put into an individual account, from which the person invests into a set of mutual funds. The PPM acts as a middleman between the individual investor who controls an account with accumulated pension rights and the mutual fund management firm that has a fund registered 
within the PPM system. The pension rights of an individual must be fully invested at all times - there is no provision for directly holding cash in the system. As a result, all sales of funds in the PPM system are simultaneously purchases of shares in other funds.

Individual investors can change the funds they are currently invested in without paying a fee. There are multiple ways of registering trades including a widely popular online system. The PPM accumulates the daily trades per fund manager, executes these as batch orders, and keeps records of the transactions. Thus the mutual fund management firm does not know the identity of each investor, only the PPM has this information.

PPM provided us with daily transaction data per mutual fund from October 2000 (when the system became operational) through September 2006. We also received information on the monthly yield of each mutual fund, its category, and its size at the start of each month. In order to focus the analysis on transactions initiated by individuals from existing funds, the data exclude transactions that were initiated by the PPM when new pension funds are allocated (PPM allocates new money according to an allocation key determined by each individual). The analysis omits the initial period of the PPM system (Oct-Dec 2000) and the first 90 days of any fund in order to eliminate the settling-in period when the pension money was initially allocated and a new fund becomes available. Except for these deletions, all available observations are used. The daily transaction data are aggregated to weekly sums of fund sales (outflows) and net flows (buys minus sales) in order to simplify the estimation of lagged effects of news. Preliminary analysis showed that scandal news affected mutual fund flows for two weeks, which is captured by entering the first and second lag of scandal news in the weekly data. The natural logarithm of sales and net flows is analyzed in order to reduce skew (for negative net flows, this involves taking the logarithm of the absolute value of the flow).

The mutual fund data are supplemented by news reports from the most widely read daily business newspaper (Dagens Industri) and the most widely read daily general newspaper (Dagens Nyheter) from January 2001 through September 2006. A text search for Skandia and reading of each article was used to code each occurrence of the phrase 'the Skandia scandal', and these were counted for each week of the sample period.

Other variables in the regressions are selected for the potential relevance to buy and sell activity in mutual funds. Monthly yield is the most recent monthly yield, in percent, of the 
fund. Ln value is the logarithm of the fund size in Swedish Kronor. Ln fund tenure is the logarithm of the time in days that the fund has existed in the PPM system. Fund type is captured through the indicator variables Interest Bearing and Mixed (the omitted category is Equity). Fund focus was coded through the indicator variables Europe, Other Region, and Industrial (the omitted category is Sweden). Some analyses replace two type and focus indicator variables by an indicator variable for each fund.

There is sustained press attention to the Skandia scandals from October 2002 through February 2005. Before that period there are two scandal mentions, and afterwards there are intermittent scandal mentions but never again two mentions in a single week. Hence in the analysis we define this time period (October 2002 through February 2005) as the scandal phase, and let the periods afterwards be the post-scandal phase. In the theory part we assumed that a random signal obtains in each "period". In reality, once a scandal outbreak occurs, a length of time sees bad news. Thus a "period" must be defined appropriately. In the descriptive analysis we only look at the trend of sales and net flows and hence it is appropriate to consolidate the (real) time periods of heated publicity into a single phase. Variations of the definition of phases produced no fundamental changes in the figures below. ${ }^{13}$ Table 1 shows the descriptive statistics of the dataset.

Modeling mutual fund flow is often done through successive cross-sectional regressions with fund characteristics such as past performance, investment style, and fee as independent variables (Fama and MacBeth, 1973; Berk and Green, 2004). Our question concerns the effect of new information (i.e., news about a scandal) on the flow of money to mutual funds rather than the average influence of for instance fee or performance. This brings our modeling needs closer to another line of finance studies that investigates the effect of new information on investor behavior (e.g., Maheu and Mccurdy, 2004). As in this literature, we need models that capture the effects of news items on the demand for a security over short time periods. The supply of stock is constant in the short term, making price changes the best measure of demand changes, but the supply of open mutual fund shares is elastic, making fund inflows and outflows the best measure of demand changes.

We found that the time series of fund sales and net flows have serial correlation in the

\footnotetext{
${ }^{13}$ In the regression analysis we use a week as a time period.
} 


\begin{tabular}{lcccc}
\hline Variable & Mean & Std. dev. & Min & Max \\
\hline & & & & \\
Ln weekly sales & 11.343 & 2.385 & 0.000 & 16.38291 \\
Ln weekly net flow & -5.421 & 10.022 & -16.38147 & 16.05789 \\
Fund type: Interest bearing & .139 & .346 & 0 & 1 \\
Fund type: Mixed & .202 & .402 & 0 & 1 \\
Fund focus: Europe & .134 & .340 & 0 & 1 \\
Fund focus: Other region & .415 & .493 & 0 & 1 \\
Fund focus: Industrial & .069 & .253 & 0 & 1 \\
Montly yield & .002 & .045 & -.239 & .175 \\
Ln value & 18.147 & 1.560 & 11.609 & 20.540 \\
Ln tenure & 6.777 & .745 & 4.500 & 7.678 \\
Scandal mentions & .427 & .929 & 0 & 5 \\
Scandals, lag 2 & .433 & .933 & 0 & 5 \\
Scandal phase & .520 & .500 & 0 & 1 \\
Post-scandal phase & .193 & .394 & 0 & 1 \\
\hline
\end{tabular}

Note: 4164 observations, 16 funds, 299 periods for each fund that existed throughout the sample period. The 'scandal phase' is from October 12002 through February 282005.

Table 1: Descriptive statistics

expectation, which we model through an autoregressive model with first and second-degree terms (an $\mathrm{AR}(2)$ model). ${ }^{14}$ They also have persistence in the volatility term, which we model through a GARCH $(1,1)$ specification (Bollerslev, 1986). We used preliminary testing to verify that the $\operatorname{AR}(2)$ model with two autoregressive terms fit better than $\operatorname{AR}(1)$ and no worse than AR(3). Models replacing the autoregressive terms with moving-average terms had worse fit than the autoregressive model. The final model is:

$$
y_{t}=\beta X_{t-1}+\rho_{1} y_{t-1}+\rho_{2} y_{t-2}+\varepsilon_{t} \sigma_{t}
$$

Where $y$ is the dependent variable, $X$ are the independent variables with associated coefficients $\beta$, and $\rho_{i}$ are the autocorrelation coefficients, as in the usual autoregressive model. The error term $\varepsilon$ is multiplied with the volatility term $\sigma_{t}$ specified as:

$$
\sigma_{t}^{2}=\omega_{1}+\omega_{2} \varepsilon_{t-1}^{2} \sigma_{t-1}^{2}+\omega_{3} \sigma_{t-1}^{2}
$$

\footnotetext{
${ }^{14}$ Theoretically, these correspond to herding effect. We are showing an additional effect of reputation.
} 


\subsection{Empirical results}

We begin with a descriptive analysis. Figure 4 shows the sum of weekly sales and net flows (buys minus sales) of Skandia brand funds expressed as a proportion of the size of the funds at the start of each month, with a count of scandal mentions in the press per week superimposed. To avoid effects of changes in the composition of funds operated by Skandia, only funds that existed throughout the sample period are graphed.

$$
===\text { Insert Figure } 4 \text { about here. }===
$$

The graph of sales shows some peaks apparently unrelated to the scandals, but a lengthy run of sales during the early scandal phase followed by two smaller runs starting at the end of the scandal phase and midway through the post-scandal phase, respectively. These sales runs are matched by runs of negative net flows in the graph below, and comparison with the reference line (zero flow) shows that there is negative net flow for most of the time after the scandal broke. Descriptively it appears like Skandia brand mutual funds suffered sales and negative net flows as a consequence of the scandals in Skandia AB.

Figure 5 shows that Skandia brand funds have indistinguishable performance from other funds in terms of monthly yield. These funds are all actively managed Swedish or World focus stock funds. The graph confirms our assumption that the bad publicity is purely a signal, not related to Skandia funds' true relative performance in the mutual fund market.

$$
===\text { Insert Figure } 5 \text { about here. }===
$$

Let us turn to the effect of the Bad signal on Skandia brand funds. Table 2 shows the mean and standard deviation in subsample weeks. The first subsamples compare weeks with and without scandals. Most weeks (201) have no scandal mention in the press in the preceding week or week before, and these weeks have lower than average sales and net outflows (negative flows). The other weeks (98) have higher sales and outflows, and these are both higher when the scandal occurred in the week before (66) than when it occurred two weeks before (32). Indeed, it appears that weeks with a scandal two weeks before but not the week before have similar flows as weeks without scandals.

The next subsamples compare the pre-scandal phase with the scandal and post-scandal phase. The pre-scandal phase has low sales and a net flow close to zero, whereas the scandal 


\begin{tabular}{lccccc}
\hline \multirow{2}{*}{ Sample } & \multicolumn{2}{c}{ Sales } & \multicolumn{2}{c}{ Net Flow } \\
& Obs. & Mean & Std. Dev. & Mean & Std. Dev. \\
\hline All observations & 299 & .00141 & .00124 & -.00092 & .00121 \\
& & & & & \\
No scandals lag 1 or 2 & 201 & .00125 & .00120 & -.00074 & .00118 \\
Scandal lag 1 or 2 & 98 & .00173 & .00127 & -.00128 & .00119 \\
Scandal lag 1 & 66 & .00188 & .00142 & -.00142 & .00134 \\
Scandal lag 2 only & 32 & .00143 & .00084 & -.00101 & .00075 \\
& & & & & \\
Pre-scandal phase & 93 & .00061 & .00075 & -.00016 & .00075 \\
Scandal phase & 124 & .00143 & .00120 & -.00102 & .00115 \\
Post-scandal phase & 82 & .00227 & .00117 & -.00163 & .00122 \\
& & & & & \\
\hline
\end{tabular}

Note. Only funds that existed throughout the sample period are included. The sales and net flow proportions are calculated based on the value of the funds at the start of the month.

Table 2: Weekly sales and net flows of Skandia brand funds

phase and post-scandal phase have higher sales and outflows. The post-scandal phase has the highest outflows, which is consistent with the theoretical implication.

In sum, we see in these figures support for the reputation dynamic. To make a more rigorous analysis, we next do regression analyses. From now on a unit of time is a week but we also keep the scandal phase indicator variables as control variables.

\subsubsection{Punishment Analysis}

The first set of analyses are shown in Tables 3 and 4 . This analysis is designed to distinguish the immediate punishment following press mentions of the scandal from the longer term punishment represented by the scandal and post-scandal phase. Immediate punishment would be seen through higher sales and net outflows following scandal mentions; lengthy punishment would be seen through higher sales and net outflows in the time periods after the scandal broke.

There is evidence of both immediate and lengthy punishment. In Table 3, both one week and two weeks lags of scandal mentions result in a significant increase in sales in the full dataset. This effect is preserved when the indicators for fund type (not displayed) are replaced with fund indicator variables in the next column, and when the data are restricted to only long-lived (third column) and equity funds (fourth column). The net flow analysis shows a similar result, though in that analysis only the second lag has a significant effect on outflows (except in the model with 
fund indicator variables). Hence immediate punishment occurs.

The time-period variables also suggest lengthy punishment. In Table 3 , both the scandal and post-scandal phase show inflated sales in all four models. In Table 4, both the scandal and post-scandal phase show higher net outflows in all four models. As the graphs suggested, the sales and outflows are not appreciably weaker in the post-scandal phase, suggesting that there is very little - if any - recovery. Next we turn to an investigation with a new variable of the scandal effect in order to get more precise answers on whether and how recovery occurs.

$$
===\text { Insert Tables } 3 \text { and } 4 \text { about here. }===
$$

\subsubsection{Recovery Analysis}

For the recovery analysis, we made a new variable (named "Recent scandals") that measures the effect of scandal mentions with fading weights on the distant past. To incorporate the distance in the past, we sum ${ }^{15}$ the counts of scandal mentions in each week with a monthly discount factor of $1-r$, where we varied $r$ between 0.1 and 0.9 in steps of 0.1 to find the factor that best fit the data. The analyses showed that small $r$ (i.e., not fading fast, or slow recovery) best fit the data. The optimal $r$ varied slightly between specifications and data sets, but for most specifications any $r$ between 0.1 and 0.3 have indistinguishable fit if we apply a Bayesian criterion of a difference in BIC statistic of 6 as presenting strong evidence that the models have different fit. The models with $r$ between 0.1 and 0.3 also have the same results. In Table 5 and Table 6 we display models that set $r=0.2$.

Table 5 displays the analysis of sales. The results are easy to summarize: for sales, there is no effect of the recent scandals in any of the specifications. All the punishment occurs immediately, which is consistent with our theoretical model. Table 6 displays the analysis of net flows. Again the results are easy to summarize: in every specification, the recent scandals variable is significant and negative. The negative coefficient means that the net flow is lower when scandals have happened recently than when they have happened a while ago. In other words, the net flow analysis shows a gradual return of customers as the time passes since the Bad signal, as our theory predicts. Because we know from Table 5 that existing customers (who can sell) do not react to the recency of scandals, it is a result of new customers purchasing Skandia funds.

\footnotetext{
${ }^{15}$ This variable counts from the third lag to avoid double counting of the first two lags.
} 
These findings are also consistent with our theory.

$===$ Insert Tables 5 and 6 about here. $===$

\section{Concluding Remarks}

We have provided a simple model of endogenous partner changes and showed that although loss of reputation is fast, recovery is slow due to the endogenous partnership formation. Our model extends the endogenous partnership literature to allow one-to-many relationships and imperfect monitoring. Our equilibrium analysis complements the literature of asymmetric fluctuation of economic variables by providing a new source of asymmetry. The usual explanation is informational externalities (Veldkamp, 2005): when there are many transactions and the economic state changes, abundant information leads to quick reaction, while when there has been few transactions, lack of information slows down the reaction. By contrast, the asymmetry occurs in our endogenous partnership model because separation is easy but formation of a new partnership is difficult. To support this theory, we also give firm-level empirical evidence.

Needless to say, the empirical evidence cannot provide support to every detail of the model. For example, we cannot distinguish whether investors who buy the Skandia funds are "newcomers" to the market or "movers" from other funds. This is because the data has aggregated daily sales by fund, and does not contain personal histories of transactions. In the data there is no other fund with a similar Bad signal during this period, and our model (taken literally) would predict that all buyers are newcomers. However, it is possible that "old" investors who have been active in the market decided to buy Skandia funds, which is a rational behavior as well, since all funds have similar performance. We did not include this possibility in the model simply because it would complicate the model and the equilibrium analysis. If there is enough loss of customers after the Bad signal, movers can also come even if no other firm had the Bad signal.

To conclude this paper we give two remarks. First, there is another line of explanation of the asymmetry via the cost of taking actions, ${ }^{16}$ in which those who have been active have smaller cost to change actions than those who have not been active in transactions. This can also explain the fast crash and slow boom. Notice that there is asymmetry of cost of taking actions as well as investor's activity level. By contrast, our model is completely symmetric across various states

\footnotetext{
${ }^{16}$ See for example, Acemoglu and Scott, (1997).
} 
of an investor: newcomers and old customers with different observations have the same payoff structure and same activity level (there is no inactive player). Thus, we have shown asymmetry even under a quite symmetric model, which is theoretically quite interesting. Moreover, as for the Skandia scandal example, the cost of changing funds is negligible, thanks to the internet and telephone trading, for any investor. Therefore the cost story is not so relevant.

Second, there are many ways that our simple model can be extended. Some extensions do not change the fundamental result of asymmetry while others may. Consider population size change. As we found in the empirical data, it is possible that new firms enter the market and/or the population size of investors change over time. Entry of new firms would negatively affect a firm with the Bad signal since fewer newcomers would choose each firm. Thus the all-effort equilibrium would hold more easily but recovery will be slower. Growth of investor population on the other hand benefits a firm with the Bad signal since more newcomers would choose each firm and thus recovery is faster.

Next, consider a different payoff structure for firms. Our computation method depends on the linearity of a firm's payoff on the customer measure. If a firm's payoff is not linear in the measure of its customers, for example if a firm can save effort cost as the customer size increases by the scale merit, then the computation in the proof of Proposition 1 fails. Endogenous movements of investors make it very difficult to explicitly solve for the total payoff of the dynamic game when this linearity is dropped. In fact, the proof of Proposition 1 is the first one that clearly solved such a dynamic game.

Finally, allowing heterogenous firms is also a complex extension. It is possible that investors have a subjective ranking among firms. (If there is an objective ranking of firms, there is no reason that lower ranked firms survive under competition.) Subjective ranking induces investorspecific movements among firms for each signal history, which will probably make the model intractable.

\section{Appendix}

\section{Proof of Proposition 1:}

Investor: As we argued in the text, investors are ex-ante indifferent among firms when all firms follow the equilibrium strategy. 
Firm: Although we simplified the strategy combination as much as possible, the signal structure makes a firm's long-run payoff heavily affected by other firms' signal histories by the movement of investors. In fact the individual firm's value function does not have the recursive structure which is often utilized in the repeated game literature. However, as we show below, the distribution of investors as a vector has a recursive structure.

Let $\mathbf{x}(t)=\left(x_{1}(t), x_{2}(t), \ldots, x_{N}(t)\right)$ be the share distribution of investors across firms $\{1,2, \ldots, N\}$ at the beginning of period $t=1,2, \ldots$. By the initial random choice of firms, $\mathbf{x}(1)=\left(\frac{1}{N}, \ldots, \frac{1}{N}\right)$.

Given $\mathbf{x}(t)$, the next period investor distribution and the share of each firm $j$ is determined by the realization of the signal in $t$.

1. If all firms had the Good signal at the end of $t$ :

Then the next period share of firm $j$, denoted as $x_{j}(t+1 ; G)$, is $x_{j}(t+1 ; G):=\delta x_{j}(t)+\frac{1-\delta}{N}$ for each $j=1,2, \ldots, N$, where $\delta x_{j}(t)$ is the "old" investors who are staying and $\frac{1-\delta}{N}$ is the "new" investors who happened to come to this firm. Thus the investor distribution (as a column vector ${ }^{17}$ ) is

$$
\mathbf{x}^{\prime}(t+1 ; G)=\delta \mathbf{x}^{\prime}(t)+\frac{1-\delta}{N} \mathbf{e}^{\prime},
$$

where $\mathbf{e}=(1,1, \ldots, 1)$ is the $N$-dimensional (row) vector.

2. If one of the firms had the Bad signal at the end of $t$ :

Let $k$ be the firm that experienced the Bad signal. For $j \neq k$, the next period share, denoted as $x_{j}(t+1 ; k B)$, is $x_{j}(t+1 ; k B):=\delta x_{j}(t)+\frac{1-\delta}{N}+\frac{1}{N-1} \delta x_{k}(t)$, where the third term is the fraction of "movers" who left firm $k$. There are $\delta x_{k}(t)$ of surviving former customers at firm $k$, and they move to the remaining $N-1$ firms with equal probability. For the firm $k$, the next period share drops to $x_{k}(t+1 ; k B):=\frac{1-\delta}{N}$, since only $1 / N$ of the newcomers would come to $k$.

Therefore, the investor distribution (again as a column vector) at $t+1$ when firm $k$ had the Bad signal at the end of $t$ can be expressed as

$$
\mathbf{x}^{\prime}(t+1 ; k B)=A_{k}(\delta) \mathbf{x}^{\prime}(t)+\frac{1-\delta}{N} \mathbf{e}^{\prime},
$$

\footnotetext{
${ }^{17}$ The notation $\left(x_{1}, x_{2}, \ldots, x_{N}\right)^{\prime}$ stands for the transpose of the row vector $\mathbf{x}=\left(x_{1}, x_{2}, \ldots, x_{N}\right)$.
} 
where the $N$ times $N$ matrix $A_{k}(\delta)$ is defined as

$$
A_{1}(\delta)=\left(\begin{array}{cccc}
0 & 0 & \cdots & 0 \\
\delta /(N-1) & \delta & \cdots & 0 \\
\vdots & 0 & \ddots & 0 \\
\delta /(N-1) & 0 & \cdots & \delta
\end{array}\right), A_{2}(\delta)=\left(\begin{array}{ccccc}
\delta & \delta /(N-1) & 0 & \cdots & 0 \\
0 & 0 & 0 & \cdots & 0 \\
0 & \delta /(N-1) & \delta & \cdots & 0 \\
0 & \vdots & 0 & \ddots & 0 \\
0 & \delta /(N-1) & 0 & \cdots & \delta
\end{array}\right)
$$

and so on.

Using this vector description, we can write the system of $N$ value functions. As long as each firm follows the constant effort strategy, the one-shot payoff in every period is $L$ times the measure of customers. Hence the value function of a firm on the play-path is $L$ times the total expected measure of customers over the infinite horizon. This simplifies the analysis considerably by allowing us to focus on the total expected measure of customers.

Let $M\left(\left(x_{1}, x_{2}, \ldots, x_{N}\right)^{\prime}\right)$ be the $N$-dimensional (column) vector of total discounted expected measure of customers of all firms, starting with the investor distribution $\left(x_{1}, x_{2}, \ldots, x_{N}\right)$ (where $\sum_{j} x_{j}=1$ ). (However, for notational convenience we allow $M$ to be defined over any $N$ dimensional column vector.) We use $\beta$-discounting so that $L M\left(\mathbf{x}^{\prime}\right)$ is exactly the total discounted expected payoff vector of firms when they make effort after any history.

From (8) and (9), $M\left(\mathbf{x}^{\prime}\right)$ is formulated recursively as follows.

$$
M\left(\mathbf{x}^{\prime}\right)=\mathbf{x}^{\prime}+\beta\left[(1-\epsilon) M\left(\delta \mathbf{x}^{\prime}+\frac{1-\delta}{N} \mathbf{e}^{\prime}\right)+\sum_{k=1}^{N} \frac{\epsilon}{N} M\left(A_{k}(\delta) \mathbf{x}^{\prime}+\frac{1-\delta}{N} \mathbf{e}^{\prime}\right)\right],
$$

as described in the text. By this formulation it is clear that $M(\cdot)$ is linear in $\mathbf{x}^{\prime}$. Explicitly, the above equation becomes

$$
\begin{aligned}
M\left(\left(\begin{array}{c}
x_{1} \\
x_{2} \\
\vdots \\
x_{N}
\end{array}\right)\right)= & \left(\begin{array}{c}
x_{1} \\
x_{2} \\
\vdots \\
x_{N}
\end{array}\right)+\beta\left[(1-\epsilon) \cdot M\left(\left(\begin{array}{c}
\delta x_{1}+(1-\delta) / N \\
\delta x_{2}+(1-\delta) / N \\
\vdots \\
\delta x_{N}+(1-\delta) / N
\end{array}\right)\right)\right. \\
& \left.+\frac{\epsilon}{N} \cdot M\left(\begin{array}{c}
\delta x_{1}+(1-\delta) / N-\delta x_{1} \\
\delta x_{2}+(1-\delta) / N+\frac{1}{N-1} \delta x_{1} \\
\vdots \\
\delta x_{N}+(1-\delta) / N+\frac{1}{N-1} x_{1}
\end{array}\right)\right) \\
& \left.+\cdots+\frac{\epsilon}{N} \cdot M\left(\left(\begin{array}{c}
\delta x_{1}+(1-\delta) / N+\frac{1}{N-1} \delta x_{N} \\
\delta x_{2}+(1-\delta) / N+\frac{1}{N-1} \delta x_{N} \\
\vdots \\
\delta x_{N}+(1-\delta) / N-\delta x_{N}
\end{array}\right)\right)\right]
\end{aligned}
$$


By the linearity of $M(\cdot)$, we have

$$
M\left(\left(\begin{array}{c}
\delta x_{1}+(1-\delta) / N \\
\delta x_{2}+(1-\delta) / N \\
\vdots \\
\delta x_{N}+(1-\delta) / N
\end{array}\right)\right)=\delta M\left(\left(\begin{array}{c}
x_{1} \\
x_{2} \\
\vdots \\
x_{N}
\end{array}\right)\right)+(1-\delta) M\left(\left(\begin{array}{c}
1 / N \\
1 / N \\
\vdots \\
1 / N
\end{array}\right)\right)
$$

and so on.

Therefore we can rearrange (10) as follows.

$$
\begin{gathered}
M\left(\left(\begin{array}{c}
x_{1} \\
x_{2} \\
\vdots \\
x_{N}
\end{array}\right)\right)=\left(\begin{array}{c}
x_{1} \\
x_{2} \\
\vdots \\
x_{N}
\end{array}\right)+\beta(1-\epsilon)\left[\delta M\left(\left(\begin{array}{c}
x_{1} \\
x_{2} \\
\vdots \\
x_{N}
\end{array}\right)\right)+(1-\delta) M\left(\left(\begin{array}{c}
1 / N \\
1 / N \\
\vdots \\
1 / N
\end{array}\right)\right)\right] \\
+\beta \frac{\epsilon}{N}\left[\delta M\left(\left(\begin{array}{c}
x_{1} \\
x_{2} \\
\vdots \\
x_{N}
\end{array}\right)\right)+(1-\delta) M\left(\left(\begin{array}{c}
1 / N \\
1 / N \\
\vdots \\
1 / N
\end{array}\right)\right)+\delta M\left(\left(\begin{array}{c}
-x_{1} \\
x_{1} /(N-1) \\
\vdots \\
x_{1} /(N-1)
\end{array}\right)\right)\right] \\
+\cdots+\beta \frac{\epsilon}{N}\left[\delta M\left(\left(\begin{array}{c}
x_{1} \\
x_{2} \\
\vdots \\
x_{N}
\end{array}\right)\right)+(1-\delta) M\left(\left(\begin{array}{c}
1 / N \\
1 / N \\
\vdots \\
1 / N
\end{array}\right)\right)+\delta M\left(\left(\begin{array}{c}
x_{N} /(N-1) \\
x_{N} /(N) \\
\vdots \\
-x_{N}
\end{array}\right)\right)\right]
\end{gathered}
$$

and furthermore

$$
\begin{gathered}
=\left(\begin{array}{c}
x_{1} \\
x_{2} \\
\vdots \\
x_{N}
\end{array}\right)+\beta\left[\delta M\left(\left(\begin{array}{c}
x_{1} \\
x_{2} \\
\vdots \\
x_{N}
\end{array}\right)\right)+(1-\delta) M\left(\left(\begin{array}{c}
1 / N \\
1 / N \\
\vdots \\
1 / N
\end{array}\right)\right)\right] \\
+\beta \frac{\epsilon}{N} \delta M\left(\left(\begin{array}{c}
-x_{1}+\sum_{j \neq 1} x_{j} /(N-1) \\
-x_{2}+\sum_{j \neq 2} x_{j} /(N-1) \\
\vdots \\
-x_{N}+\sum_{j \neq N} x_{j} /(N-1)
\end{array}\right)\right) .
\end{gathered}
$$

Using $\sum_{j} x_{j}=1$, we have

$$
\begin{aligned}
M\left(\left(\begin{array}{c}
x_{1} \\
x_{2} \\
\vdots \\
x_{N}
\end{array}\right)\right)= & \left(\begin{array}{c}
x_{1} \\
x_{2} \\
\vdots \\
x_{N}
\end{array}\right)+\beta\left[\delta M\left(\left(\begin{array}{c}
x_{1} \\
x_{2} \\
\vdots \\
x_{N}
\end{array}\right)\right)+(1-\delta) M\left(\left(\begin{array}{c}
1 / N \\
1 / N \\
\vdots \\
1 / N
\end{array}\right)\right)\right] \\
& +\beta \frac{\epsilon}{N} \delta M\left(\left(\begin{array}{c}
-x_{1}+\left(1-x_{1}\right) /(N-1) \\
-x_{2}+\left(1-x_{2}\right) /(N-1) \\
\vdots \\
-x_{N}+\left(1-x_{N}\right) /(N-1)
\end{array}\right)\right)
\end{aligned}
$$


Hence the long-run measure of customers is independent from the initial measure of other firms' customers. This is because all firms have the same random signal structure.

By further rearrangements we get

$$
\begin{aligned}
& M\left(\left(\begin{array}{c}
x_{1} \\
x_{2} \\
\vdots \\
x_{N}
\end{array}\right)\right)=\left(\begin{array}{c}
x_{1} \\
x_{2} \\
\vdots \\
x_{N}
\end{array}\right)+\beta\left[\delta M\left(\left(\begin{array}{c}
x_{1} \\
x_{2} \\
\vdots \\
x_{N}
\end{array}\right)\right)+(1-\delta) M\left(\left(\begin{array}{c}
1 / N \\
1 / N \\
\vdots \\
1 / N
\end{array}\right)\right)\right] \\
& +\beta \frac{\epsilon}{N} \delta\left[M\left(\left(\begin{array}{c}
1 /(N-1) \\
1 /(N-1) \\
\vdots \\
1 /(N-1)
\end{array}\right)\right)-\frac{N}{N-1} M\left(\left(\begin{array}{c}
x_{1} \\
x_{2} \\
\vdots \\
x_{N}
\end{array}\right)\right)\right] \\
& =\left(\begin{array}{c}
x_{1} \\
x_{2} \\
\vdots \\
x_{N}
\end{array}\right)+\beta \delta M\left(\left(\begin{array}{c}
x_{1} \\
x_{2} \\
\vdots \\
x_{N}
\end{array}\right)\right)+\beta(1-\delta) M\left(\left(\begin{array}{c}
1 / N \\
1 / N \\
\vdots \\
1 / N
\end{array}\right)\right) \\
& +\beta \delta \frac{\epsilon}{N-1} M\left(\left(\begin{array}{c}
1 / N \\
1 / N \\
\vdots \\
1 / N
\end{array}\right)\right)-\beta \delta \frac{\epsilon}{N-1} M\left(\left(\begin{array}{c}
x_{1} \\
x_{2} \\
\vdots \\
x_{N}
\end{array}\right)\right) \\
& =\left(\begin{array}{c}
x_{1} \\
x_{2} \\
\vdots \\
x_{N}
\end{array}\right)+\left\{\beta \delta-\beta \delta \frac{\epsilon}{N-1}\right\} M\left(\left(\begin{array}{c}
x_{1} \\
x_{2} \\
\vdots \\
x_{N}
\end{array}\right)\right)+\left\{\beta(1-\delta)+\beta \delta \frac{\epsilon}{N-1}\right\} M\left(\left(\begin{array}{c}
1 / N \\
1 / N \\
\vdots \\
1 / N
\end{array}\right)\right) .
\end{aligned}
$$

Finally, multiplying both sides with $(N-1)$ and moving $M\left(\left(x_{1}, \ldots, x_{N}\right)^{\prime}\right)$ to the LHS, we have an explicit formula:

$$
\{(N-1)(1-\beta \delta)+\beta \delta \epsilon\} M\left(\left(\begin{array}{c}
x_{1} \\
x_{2} \\
\vdots \\
x_{N}
\end{array}\right)\right)=(N-1)\left(\begin{array}{c}
x_{1} \\
x_{2} \\
\vdots \\
x_{N}
\end{array}\right)+\{(N-1) \beta(1-\delta)+\beta \delta \epsilon\} M\left(\left(\begin{array}{c}
1 / N \\
1 / N \\
\vdots \\
1 / N
\end{array}\right)\right) .
$$

In particular, when $x_{j}=1 / N$ for all $j,(12)$ gives an explicit solution such that

$$
M\left(\left(\begin{array}{c}
1 / N \\
1 / N \\
\vdots \\
1 / N
\end{array}\right)\right)=\frac{1}{1-\beta}\left(\begin{array}{c}
1 / N \\
1 / N \\
\vdots \\
1 / N
\end{array}\right)
$$

This makes sense, since starting from the same measure of customers and with the stationary and symmetric transition rule, all firms' total expected measure of customers must be the same 
and on average $1 / N$. Plugging (13) into (12), we have the total expected discounted measure of customers of firm $j$, starting from an arbitrary distribution:

$$
M_{j}\left(x_{j}\right)=\frac{(N-1) x_{j}+\{(N-1) \beta(1-\delta)+\beta \delta \epsilon\} \frac{1}{(1-\beta) N}}{(N-1)(1-\beta \delta)+\beta \delta \epsilon} .
$$

For any firm $j$ and any starting measure of customers $x_{j}$, the firm does not deviate in one step if and only if

$$
L \cdot M_{j}\left(x_{j}\right) \geqq H \cdot x_{j}+\beta L \cdot M_{j}\left(\frac{1-\delta}{N}\right) .
$$

By (14), the above no-deviation condition (4) is equivalent to

$$
[L(N-1)-\{(N-1)(1-\beta \delta)+\beta \delta \epsilon\} H] x_{j} \geqq-\frac{\beta \delta \epsilon L}{N} .
$$

When both investors and firms are very patient, $\beta \delta \rightarrow 1$ so that the LHS of (15) converges to $[L(N-1)-\epsilon H] x_{j}$. Thus, if $\epsilon<L(N-1) / H$, then (15) holds for sufficiently large $(\beta, \delta)$.

Proof of Corollary 1: From (13), when $x_{j}=\frac{1}{N}$,

$$
L \cdot M_{j}\left(\frac{1}{N}\right)=\frac{L}{N(1-\beta)} .
$$

This is the equilibrium payoff of a firm.

Proof of Proposition 2: Notice that the only change of $M(\cdot)$ formulation under the new strategy combination is that, when firm $k$ gets Bad signal, $\delta \alpha x_{k}$ is the measure of movers from firm $k$, who are distributed among $N-1$ other firms. Let us denote the new total discounted expected measure of customers as $M^{\alpha}(\cdot)$. (11) now becomes

$$
\begin{aligned}
& M^{\alpha}\left(\left(\begin{array}{c}
x_{1} \\
x_{2} \\
\vdots \\
x_{N}
\end{array}\right)\right)=\left(\begin{array}{c}
x_{1} \\
x_{2} \\
\vdots \\
x_{N}
\end{array}\right)+\beta(1-\epsilon)\left[\delta M^{\alpha}\left(\left(\begin{array}{c}
x_{1} \\
x_{2} \\
\vdots \\
x_{N}
\end{array}\right)\right)+(1-\delta) M^{\alpha}\left(\left(\begin{array}{c}
1 / N \\
1 / N \\
\vdots \\
1 / N
\end{array}\right)\right)\right] \\
& +\beta \frac{\epsilon}{N}\left[\delta M^{\alpha}\left(\left(\begin{array}{c}
x_{1} \\
x_{2} \\
\vdots \\
x_{N}
\end{array}\right)\right)+(1-\delta) M^{\alpha}\left(\left(\begin{array}{c}
1 / N \\
1 / N \\
\vdots \\
1 / N
\end{array}\right)\right)+\delta M^{\alpha}\left(\left(\begin{array}{c}
\alpha x_{1} /(N-1) \\
\vdots \\
\alpha x_{1} /(N-1)
\end{array}\right)\right)\right] \\
& \left.+\cdots+\beta \frac{\epsilon}{N}\left[\delta M^{\alpha}\left(\left(\begin{array}{c}
x_{1} \\
x_{2} \\
\vdots \\
x_{N}
\end{array}\right)\right)+(1-\delta) M^{\alpha}\left(\begin{array}{c}
\alpha x_{N} /(N-1) \\
\alpha x_{N} /(N-1) \\
1 / N \\
\vdots \\
1 / N
\end{array}\right)\right)+\delta M^{\alpha}\left(\left(\begin{array}{c}
1 / N \\
-\alpha x_{N}
\end{array}\right)\right)\right](17)
\end{aligned}
$$


By similar arrangements as in the proof of Proposition 1, we have an explicit formula: $\{(N-1)(1-\beta \delta)+\alpha \beta \delta \epsilon\} M^{\alpha}\left(\left(\begin{array}{c}x_{1} \\ x_{2} \\ \vdots \\ x_{N}\end{array}\right)\right)=(N-1)\left(\begin{array}{c}x_{1} \\ x_{2} \\ \vdots \\ x_{N}\end{array}\right)+\{(N-1) \beta(1-\delta)+\alpha \beta \delta \epsilon\} M^{\alpha}\left(\left(\begin{array}{c}1 / N \\ 1 / N \\ \vdots \\ 1 / N\end{array}\right)\right)$.

When $x_{j}=1 / N$ for all $j$, we again have

$$
\left.M^{\alpha}\left(\begin{array}{c}
1 / N \\
1 / N \\
\vdots \\
1 / N
\end{array}\right)\right)=\frac{1}{1-\beta}\left(\begin{array}{c}
1 / N \\
1 / N \\
\vdots \\
1 / N
\end{array}\right)
$$

and thus

$$
M_{j}^{\alpha}\left(x_{j}\right)=\frac{(N-1) x_{j}+\{(N-1) \beta(1-\delta)+\alpha \beta \delta \epsilon\} \frac{1}{(1-\beta) N}}{(N-1)(1-\beta \delta)+\alpha \beta \delta \epsilon} .
$$

Therefore, the condition that firm $j$ does not deviate in one step;

$$
L \cdot M_{j}^{\alpha}\left(x_{j}\right) \geqq H \cdot x_{j}+\beta L \cdot M_{j}^{\alpha}\left(\frac{1-\delta}{N}\right)
$$

is satisfied if and only if

$$
[L(N-1)-\{(N-1)(1-\beta \delta)+\alpha \beta \delta \epsilon\} H] x_{j} \geqq-\frac{\alpha \beta \delta \epsilon L}{N} .
$$

When $\beta \delta \rightarrow 1$, this condition converges to

$$
[L(N-1)-\alpha \epsilon H] x_{j} \geqq-\frac{\alpha \epsilon L}{N} .
$$

which is satisfied if $\epsilon \leqq \frac{L(N-1)}{\alpha H}$. Hence, for any $\epsilon$, there exists $\bar{\alpha}>0$ such that no firm deviates in one step for any $\alpha \leqq \bar{\alpha}$.

\section{References}

Abreu, D., D. Pearce, and E. Stachetti. (1986) "Optimal Cartel Equilibria with Imperfect Monitoring", Journal of Economic Theory 39: 251-269.

Abreu, D., D. Pearce, and E. Stachetti. (1990) "Toward a Theory of Discounted Repeated Games with Imperfect Monitoring", Econometrica 58: 1041-1063.

Acemoglu, D. and A. Scott. (1997) "Asymmetric Business Cycles: Theory and Time-Series Evidence", Journal of Monetary Economics, 40, 501-533. 
Berk J. and R. Green (2004). "Mutual Fund Flows and Performance in Rational Markets." Journal of Political Economy, 112: 1269?1295

Bollerslev, T.(1986) "Generalized autoregressive conditional heteroskedasticity." Journal of Econometrics, 31: 307-327.

Ely, J. and J. Välimäki. (2002) “A Robust Folk Theorem for the Prisoner's Dilemma.” Journal of Economic Theory, 102, 84-105.

Fama, E., and J MacBeth. (1973) "Risk, Return, and Equilibrium; Empirical Tests." Journal of Political Economy, 81: 607-636.

Fujiwara-Greve, T., and M. Okuno-Fujiwara (2009) "Voluntarily Separable Repeated Prisoner's Dilemma," Review of Economic Studies, 76(3), 993-1021.

Ghosh, P., and D. Ray (1996): "Cooperation in Community Interaction without Information Flows," Review of Economic Studies, 63, 491-519.

Green, E., and R. Porter. (1984) "Noncooperatiove Collusion under Imperfect Price Information", Econometrica, 52: 87-100.

Hirshman, A. (1970) Exit, Voice, and Loyalty: Responses to Decline in Firms, Organizations, and States, Cambridge University Press (Cambridge, UK).

Horngren, L. (2001) "Pension reform: The Swedish case." Journal of Pensions Management, 7: 131.

Jonsson, S., H. Greve, and T. Fujiwara-Greve. (2009) "Undeserved Loss: The Spread of Legitimacy Loss to Innocent Organizations in Response to Reporated Corporate Deviance." Administrative Science Quarterly, 54: 195-228.

Kandori, M. (2002). "Introduction to Repeated Games with Private Monitoring", Journal of Economic Theory 102: 1- 15.

Klein, B. and K. Leffler. (1981) "The Role of Market Forces in Assuring Contractual Performance", Journal of Political Economy 89: 615-641.

Kranton, R. (1996a): "The Formation of Cooperative Relationships," Journal of Law, Economics, \& Organization 12, 214-233.

Kranton, R. (1996b): "Reciprocal Exchange: A Self-Sustaining System," American Economic Review, 86, 830-851.

Kreps, D. (1990) "Corporate Culture and Economic Theory", in Alt and Shepsle (eds.) Perspec- 
tives on Positive Political Economy, Cambridge University Press (Cambridge, UK), 132-154.

Maheu, J. M. and McCurdy, T. H. (2004) "News arrival, jump dynamics, and volatility components for individual stock returns", Journal of Finance, 59: 755-793.

Mailath, G. and S. Morris. (2002) "Repeated Games with Almost-public Monitoring", Journal of Economic Theory 102: 189-228.

McKay, A. and R. Reis. (2008) "The Brevity and Violence of Contractions and Expansions", Journal of Monetary Economics, 55(4), 738-751.

Neftci, S. (1984) "Are Economic Time Series Asymmetric over the Business Cycle?", Journal of Political Economy, 92, 307-328.

van Nieuwerburgh, S. and L. Veldkamp. (2006) "Learning Asymmetries in Real Business Cycles", Journal of Monetary Economics, 53: 753-772.

Radner, R. (1980) "Collusive Behaviour in Noncooperative Epsilon-Equilibria of Oligopolies with Long but Finite Lives", Journal of Economic Theory, 22, 136-154.

Sunden, A. (1998) "The Swedish NDC Pension Reform", Annals of Public and Cooperative Economics, 69: 571-583.

Veldkamp, L. (2005): "Slow Boom, Sudden Crash", Journal of Economic Theory, 124: 230-257.

Yasuda, Y. (2007): "The theory of collusion under financial constraints." manuscript, GRIPS, Tokyo. 

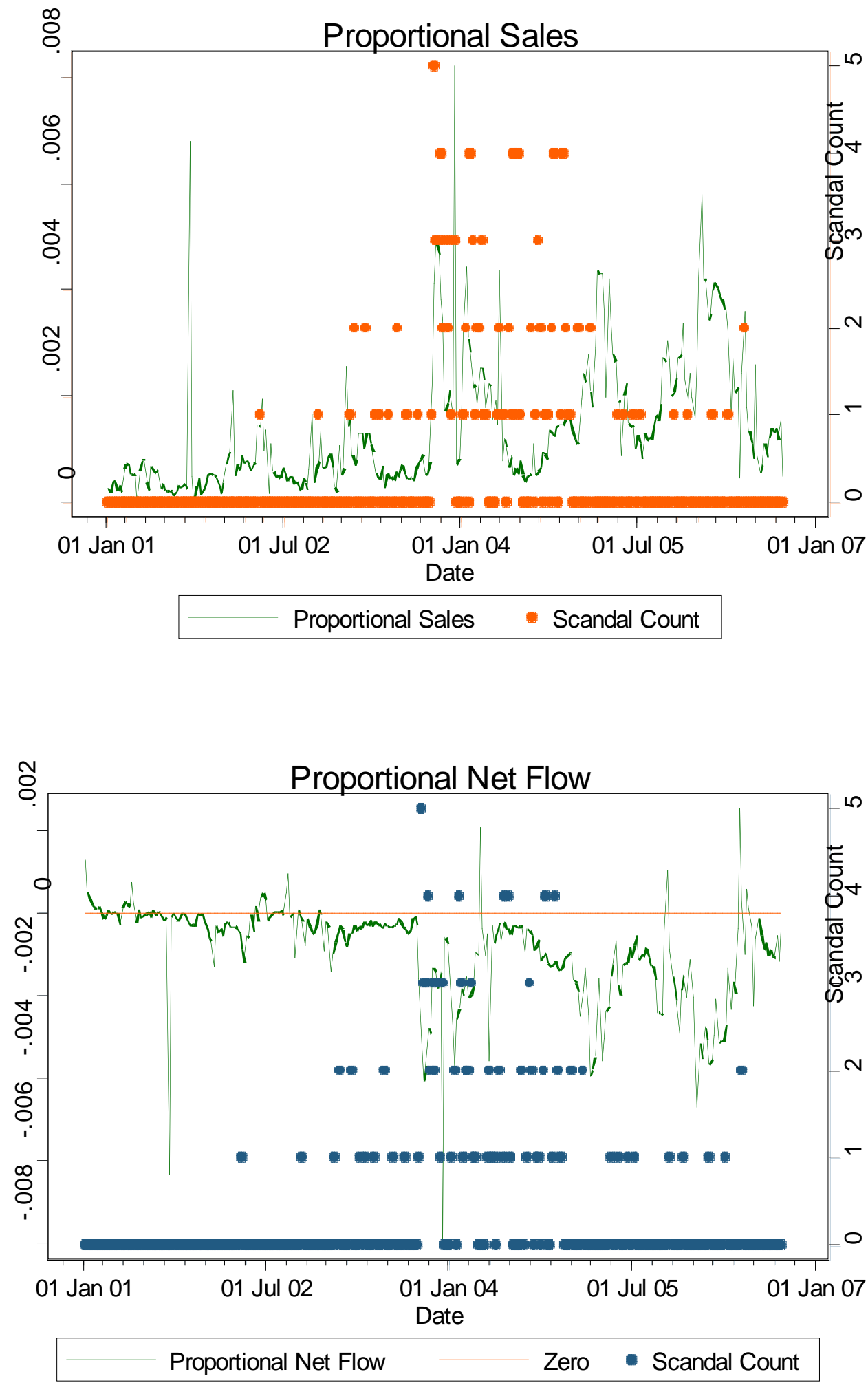

Figure 4: Weekly sales and net flow aggregated over Skandia's long-lived funds 

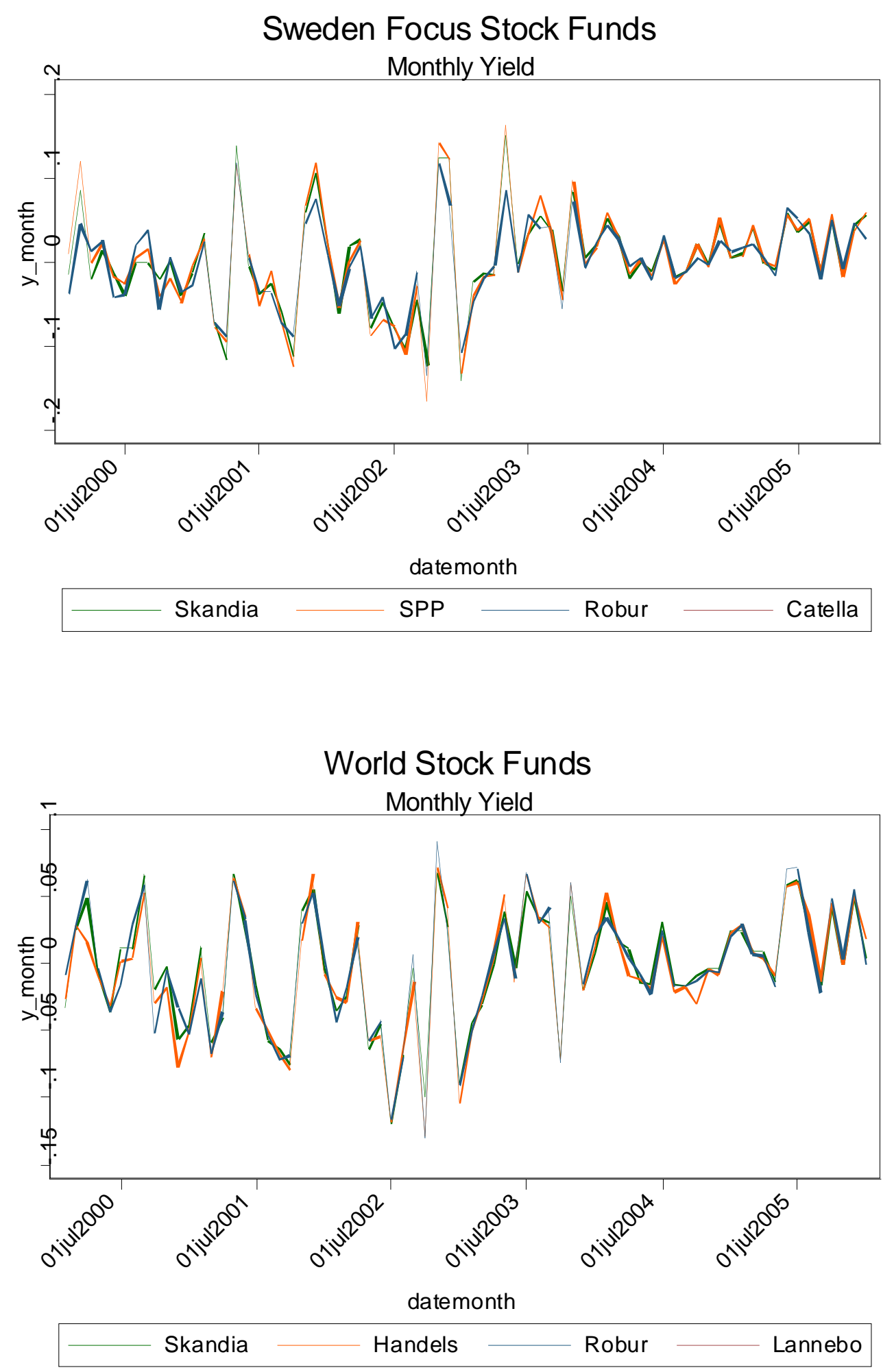

Figure 5: Performance comparison with other funds 


\begin{tabular}{lcccc}
\hline & & & & \\
Funds & All funds & All funds & Long lived & Only equity \\
\hline \multirow{4}{*}{ Indicators } & Category & Fund & Category & Category \\
\hline \multirow{3}{*}{ Monthly yield } & -0.867 & -0.122 & -0.403 & -1.009 \\
& $(1.97)^{*}$ & $(0.28)$ & $(0.87)$ & $(2.30)^{*}$ \\
Ln value & 0.439 & -0.036 & 0.782 & 0.497 \\
& $(8.26)^{* *}$ & $(0.28)$ & $(18.00)^{* *}$ & $(10.23)^{* *}$ \\
Ln tenure & 2.085 & 2.342 & 1.980 & 2.190 \\
& $(16.82)^{* *}$ & $(20.52)^{* *}$ & $(20.26)^{* *}$ & $(18.04)^{* *}$ \\
Scandal mentions & 0.023 & 0.034 & 0.029 & 0.020 \\
& $(1.98)^{*}$ & $(2.78)^{* *}$ & $(2.27)^{*}$ & $(1.49)$ \\
Scandals, lag 2 & 0.028 & 0.030 & 0.035 & 0.025 \\
& $(2.49)^{*}$ & $(2.60)^{* *}$ & $(3.05)^{* *}$ & $(2.03)^{*}$ \\
Scandal phase & 1.311 & 0.594 & 0.710 & 0.986 \\
Post-scandal ph. & $(6.95)^{* *}$ & $(4.20)^{* *}$ & $(4.74)^{* *}$ & $(5.42)^{* *}$ \\
& 1.459 & 0.795 & 0.784 & 1.108 \\
Constant & $(6.28)^{* *}$ & $(4.41)^{* *}$ & $(4.28)^{* *}$ & $(4.99)^{* *}$ \\
& -12.827 & -4.854 & -18.060 & -14.309 \\
& $(12.55)^{* *}$ & $(2.84)^{* *}$ & $(19.31)^{* *}$ & $(14.26)^{* *}$ \\
Observations & 4164 & 4164 & 3456 & 3321 \\
Log likelihood & -6026.70 & -5869.23 & -4616.95 & -4811.98 \\
LR Chi2 & 3587.00 & 3532.94 & 3361.13 & 2696.62 \\
df & 14 & 23 & 14 & 13 \\
& & & & \\
\hline
\end{tabular}

Note. Absolute values of $\mathrm{z}$ statistics are shown in parentheses.

$\operatorname{GARCH}(1,1)$ model with $\mathrm{AR}(2)$. Indicator variables for category and type of fund except in the model with Fund indicator variables.

Table 3: Regression of weekly sales per Skandia brand fund 


\begin{tabular}{lcccc}
\hline & & & & \\
Funds & All funds & All funds & Long lived & Only equity \\
\hline \multirow{2}{*}{ Indicators } & Category & Fund & Category & Category \\
\hline \multirow{2}{*}{ Monthly yield } & 6.444 & 0.203 & 6.656 & 6.393 \\
& $(5.81)^{* *}$ & $(0.18)$ & $(5.96)^{* *}$ & $(5.55)^{* *}$ \\
Ln value & -3.851 & 1.157 & -4.486 & -3.786 \\
& $(31.12)^{* *}$ & $(5.20)^{* *}$ & $(26.90)^{* *}$ & $(29.18)^{* *}$ \\
Ln tenure & -1.272 & -2.021 & -1.520 & -1.825 \\
& $(5.73)^{* *}$ & $(7.55)^{* *}$ & $(6.12)^{* *}$ & $(7.52)^{* *}$ \\
Scandal mentions & -0.018 & 0.015 & -0.005 & -0.004 \\
& $(0.70)$ & $(0.72)$ & $(0.19)$ & $(0.14)$ \\
Scandals, lag 2 & -0.071 & 0.009 & -0.065 & -0.063 \\
Scandal phase & $(3.01)^{* *}$ & $(0.44)$ & $(2.78)^{* *}$ & $(2.67)^{* *}$ \\
Post-scandal ph. & -3.399 & -5.318 & -2.996 & -3.006 \\
& $(10.85)^{* *}$ & $(15.11)^{* *}$ & $(9.19)^{* *}$ & $(8.80)^{* *}$ \\
Constant & -2.690 & -6.263 & -2.496 & -2.718 \\
& $(6.96)^{* *}$ & $(15.91)^{* *}$ & $(6.18)^{* *}$ & $(6.55)^{* *}$ \\
& 74.933 & 2.533 & 88.372 & 77.296 \\
Observations & $(32.23)^{* *}$ & $(0.90)$ & $(30.69)^{* *}$ & $(31.79)^{* *}$ \\
Log likelihood & 4164 & 4164 & 3456 & 3321 \\
LR Chi2 & -13182.67 & -13053.27 & -10394.98 & -9919.95 \\
df & 2668.10 & 4206.88 & 2545.28 & 2218.33 \\
& 14 & 23 & 14 & 13 \\
\hline & & & & \\
\hline
\end{tabular}

Note. Absolute values of $\mathrm{z}$ statistics are shown in parantheses.

$\operatorname{GARCH}(1,1)$ model with $\mathrm{AR}(2)$. Indicator variables for category and type of fund except in the model with Fund indicator variables.

Table 4: Regression of weekly net flow per Skandia brand fund 


\begin{tabular}{lcccc}
\hline & & & & \\
Funds & All funds & All funds & Long lived & Only equity \\
\hline \multirow{4}{*}{ Indicators } & Category & Fund & Category & Category \\
\hline \multirow{3}{*}{ Monthly yield } & -0.872 & -0.123 & -0.403 & -1.025 \\
& $(1.98)^{*}$ & $(0.28)$ & $(0.88)$ & $(2.33)^{*}$ \\
Ln value & 0.439 & -0.033 & 0.783 & 0.500 \\
& $(8.25)^{* *}$ & $(0.25)$ & $(18.05)^{* *}$ & $(10.27)^{* *}$ \\
Ln tenure & 2.081 & 2.346 & 1.973 & 2.173 \\
& $(16.56)^{* *}$ & $(20.38)^{* *}$ & $(19.85)^{* *}$ & $(17.60)^{* *}$ \\
Scandal mentions & 0.024 & 0.034 & 0.029 & 0.021 \\
& $(1.98)^{*}$ & $(2.70)^{* *}$ & $(2.30)^{*}$ & $(1.58)$ \\
Scandals, lag 2 & 0.028 & 0.029 & 0.036 & 0.026 \\
& $(2.48)^{*}$ & $(2.55)^{*}$ & $(3.07)^{* *}$ & $(2.12)^{*}$ \\
Scandal phase & 1.306 & 0.602 & 0.700 & 0.967 \\
& $(6.86)^{* *}$ & $(4.17)^{* *}$ & $(4.60)^{* *}$ & $(5.26)^{* *}$ \\
Post-scandal ph. & 1.464 & 0.789 & 0.790 & 1.124 \\
& $(6.28)^{* *}$ & $(4.36)^{* *}$ & $(4.30)^{* *}$ & $(5.04)^{* *}$ \\
Recent scandals & 0.002 & -0.002 & 0.003 & 0.006 \\
& $(0.22)$ & $(0.28)$ & $(0.36)$ & $(0.70)$ \\
Constant & -12.821 & -4.925 & -18.038 & -14.268 \\
& $(12.54)^{* *}$ & $(2.89)^{* *}$ & $(19.31)^{* *}$ & $(14.22)^{* *}$ \\
Observations & 4164 & 4164 & 3456 & 3321 \\
Log likelihood & -6026.67 & -5869.19 & -4616.88 & -4811.74 \\
LR Chi2 & 3582.76 & 3544.94 & 3353.45 & 2682.63 \\
df & 15 & 24 & 15 & 14 \\
& & & & \\
\hline
\end{tabular}

Note. Absolute values of $\mathrm{z}$ statistics are shown in parentheses.

$\operatorname{GARCH}(1,1)$ model with $\mathrm{AR}(2)$. Indicator variables for category and type of fund except in the model with Fund indicator variables.

Table 5: Regression of weekly sales per Skandia brand fund 


\begin{tabular}{lcccc}
\hline & & & & \\
Funds & All funds & All funds & Long lived & Only equity \\
\hline \multirow{2}{*}{ Indicators } & Category & Fund & Category & Category \\
\hline \multirow{2}{*}{ Monthly yield } & 4.428 & 3.509 & 6.232 & 6.373 \\
& $(3.56)^{* *}$ & $(3.21)^{* *}$ & $(5.45)^{* *}$ & $(5.50)^{* *}$ \\
Ln value & -3.298 & -0.527 & -4.468 & -4.013 \\
& $(21.85)^{* *}$ & $(1.60)$ & $(26.98)^{* *}$ & $(28.71)^{* *}$ \\
Ln tenure & -1.684 & -2.973 & -1.360 & -1.120 \\
& $(5.43)^{* *}$ & $(9.59)^{* *}$ & $(5.33)^{* *}$ & $(4.66)^{* *}$ \\
Scandal mentions & 0.017 & -0.014 & -0.009 & -0.016 \\
& $(0.61)$ & $(0.55)$ & $(0.37)$ & $(0.67)$ \\
Scandals, lag 2 & -0.047 & -0.039 & -0.067 & -0.065 \\
& $(1.78)+$ & $(1.71)+$ & $(2.90)^{* *}$ & $(2.89)^{* *}$ \\
Scandal phase & -2.769 & -2.708 & -2.818 & -3.447 \\
& $(6.37)^{* *}$ & $(7.19)^{* *}$ & $(8.41)^{* *}$ & $(9.54)^{* *}$ \\
Post-scandal ph. & -2.790 & -3.259 & -2.601 & -3.068 \\
& $(5.45)^{* *}$ & $(7.67)^{* *}$ & $(6.43)^{* *}$ & $(7.18)^{* *}$ \\
Recent scandals & -0.042 & -0.030 & -0.049 & -0.068 \\
& $(3.00)^{* *}$ & $(2.34)^{*}$ & $(3.54)^{* *}$ & $(4.98)^{* *}$ \\
Constant & 66.660 & 30.907 & 87.101 & 77.481 \\
& $(22.55)^{* *}$ & $(7.54)^{* *}$ & $(30.29)^{* *}$ & $(30.18)^{* *}$ \\
Observations & 4164 & 4164 & 3456 & 3321 \\
Log likelihood & -13139.52 & -13081.16 & -10388.73 & -9927.38 \\
LR Chi2 & 1933.72 & 3520.38 & 2516.09 & 2099.02 \\
df & 15 & 24 & 15 & 14 \\
& & & & \\
\hline
\end{tabular}

Note. Absolute values of $\mathrm{z}$ statistics are shown in parentheses.

$\operatorname{GARCH}(1,1)$ model with $\mathrm{AR}(2)$. Indicator variables for category and type of fund except in the model with Fund indicator variables.

Table 6: Regression of weekly net flow per Skandia brand fund 